\title{
DEVELOPMENT OF GEOTHERMALLY ASSISTED PROCESS FOR PRODUCTION OF LIQUID FUELS AND CHEMICALS FROM WHEAT STRAW
}

June 1981

\author{
Prepared by \\ Dept. of Agricultural and Chemical Engineering \\ Colorado State University \\ Fort Collins, $\mathrm{CO} 80523$ \\ For \\ EG\&G Idaho, Inc. \\ Idaho Falls, ID 83415 \\ and the \\ U.S. Department of Energy \\ Idaho Operations Office \\ Under Contract No. DE-AS07-79ID12051
}




\section{DISCLAIMER}

This report was prepared as an account of work sponsored by an agency of the United States Government. Neither the United States Government nor any agency Thereof, nor any of their employees, makes any warranty, express or implied, or assumes any legal liability or responsibility for the accuracy, completeness, or usefulness of any information, apparatus, product, or process disclosed, or represents that its use would not infringe privately owned rights. Reference herein to any specific commercial product, process, or service by trade name, trademark, manufacturer, or otherwise does not necessarily constitute or imply its endorsement, recommendation, or favoring by the United States Government or any agency thereof. The views and opinions of authors expressed herein do not necessarily state or reflect those of the United States Government or any agency thereof. 


\section{DISCLAIMER}

Portions of this document may be illegible in electronic image products. Images are produced from the best available original document. 


\section{Printed in the United States of America}

Available from

National Technical Information Service

U.S. Department of Commerce

5285 Port Royal Road

Springfield, VA 22161

NTIS Price Codes: Printed Copy A04

Microfiche A01

\section{DISCLAIMER}

This book was prepared as an account of work sponsored by an agency of the United States Government. Neither the United States Government nor any agency thereof, nor any of their employees, makes any warranty, express or implied, or assumes any legal liability or responsibility for the accuracy, completeness, or usefulness of any information, apparatus, product or process disclosed, or represents that its use would not infringe privately owned rights. References herein to any specific commercial product, process, or service by trade name, trademark, manufacturer, or otherwise, does not necessarily constitute or imply its endorsement, recommendation, or favoring by the United States Government or any agency thereof. The views and opinions of authors expressed herein do not necessarily state or reflect those of the United States Government or any agency thereof. 


\section{DEVELOPMENT OF GEOTHERMALLY ASSISTED \\ PROCESS FOR PRODUCTION OF LIQUID \\ FUELS AND CHEMICALS FROM WHEAT STRAW}

Topical Report

By:

V. G. Murphy

J. C. Linden

A. R. Moreira

T. G. Lenz

June 1981

Prepared by

Department of Agricultural and Chemical Engineering

Colorado State University

Fort Collins, Co 80523

For

EG\&G Idaho, Inc.

Idaho Falls, ID 83401

and the

U.S. Department of Energy

Idaho Operations office

Under Contract No. DE-AS07-79ID12051 

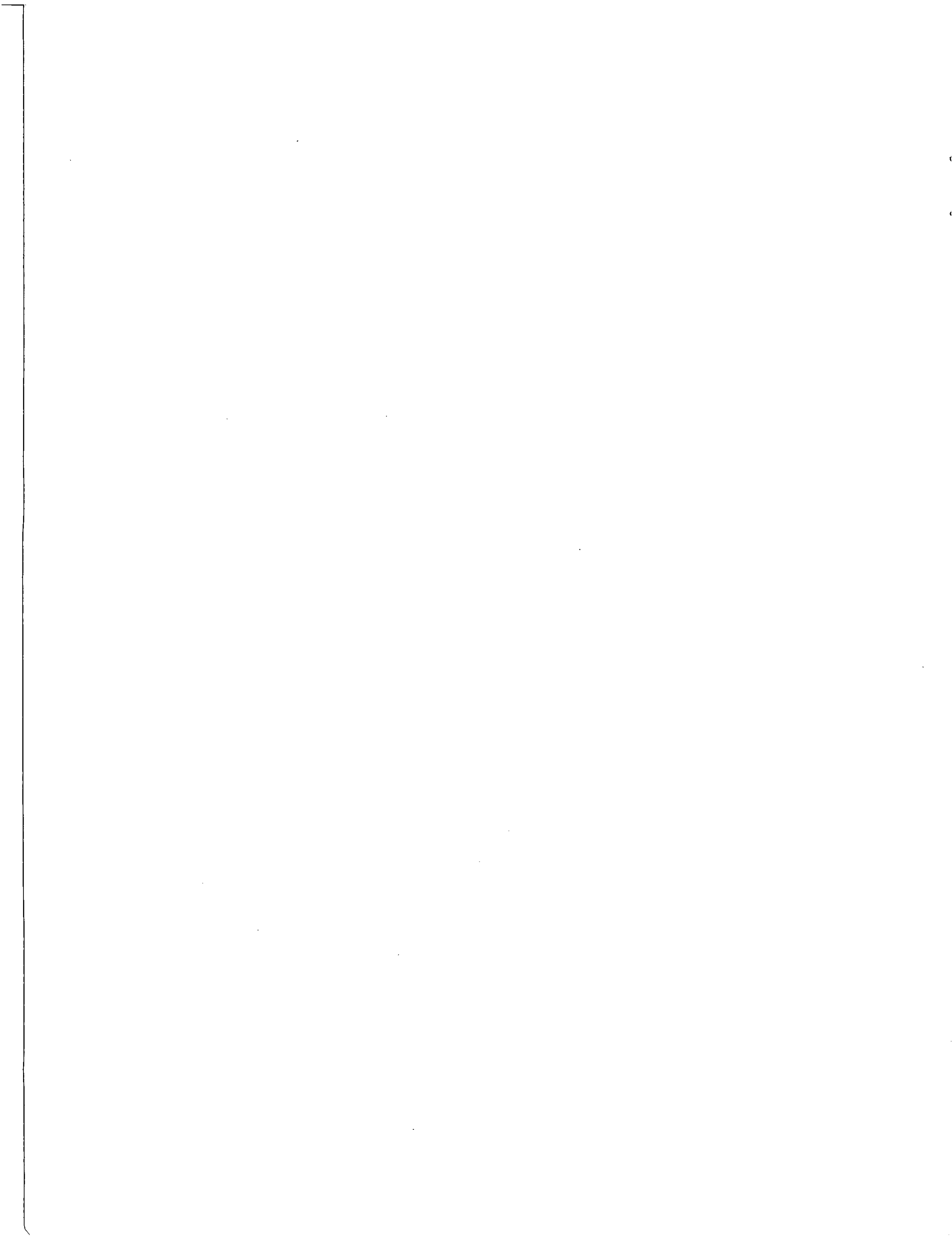
TABLE OF CONTENTS

\section{LIST OF TABLES \\ LIST OF FIGURES}

INTRODUCTION

MATERIALS AND METHODS

Reagents

Procedures

Analytical Methods

RESULTS AND DISCUSSION

Autohydrolysis Studies

Enzymatic Hydrolysis Studies

Fermentation Study

Effects of Direct Use of Geothermal Water

RECOMMENDATIONS FOR FUTURE WORK 


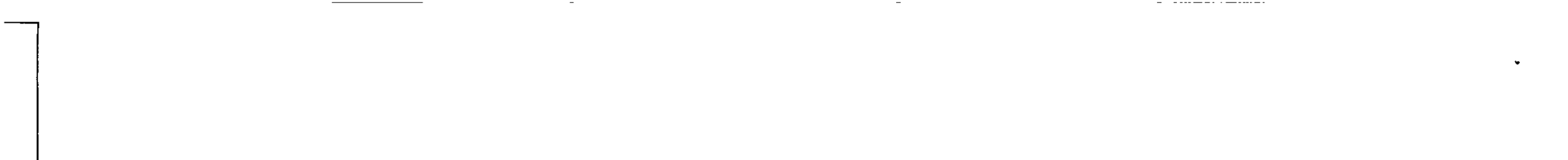


1. Yields of some sugars and sugar degradation products during autohydrolysis of wheat straw at $120^{\circ} \mathrm{C}$.

2. Yields of some sugars and sugar degradation products during autohydrolysis of wheat straw at $120^{\circ} \mathrm{C}$ in the presence of aluminum sulfate.

3. Yields of some sugars and sugar degradation products during autohydrolysis of wheat straw at $155^{\circ} \mathrm{C}$.

4. Yields of some sugars and sugar degradation products during autohydrolysis of wheat straw at $155^{\circ} \mathrm{C}$ in the presence of aluminum sulfate.

5. Yields of some sugars and sugar degradation products during autohydrolysis of wheat straw at $180^{\circ} \mathrm{C}$.

6. Yields of some sugars and sugar degradation products during autohydrolysis of wheat straw at $180^{\circ} \mathrm{C}$ in the presence of aluminum sulfate.

7. Effect of autohydrolysis on composition of wheat straw.

8. Initial compositions of reaction mixtures used in study of kinetics of enzymatic hydrolysis of autohydrolyzed wheat straw.

9. Yield of reducing sugar at various times during enzyme hydrolysis of autohydrolyzed wheat straw.

10. Concentration of reducing sugar at various times during enzyme hydrolysis of autohydrolyzed wheat straw.

11. Fiber analysis data for wheat straw samples at different processing stages.

12. Medium composition for baker's yeast fermentation.

13. Effect of geothermal water on the fermentation of dextrose with baker's yeast. 

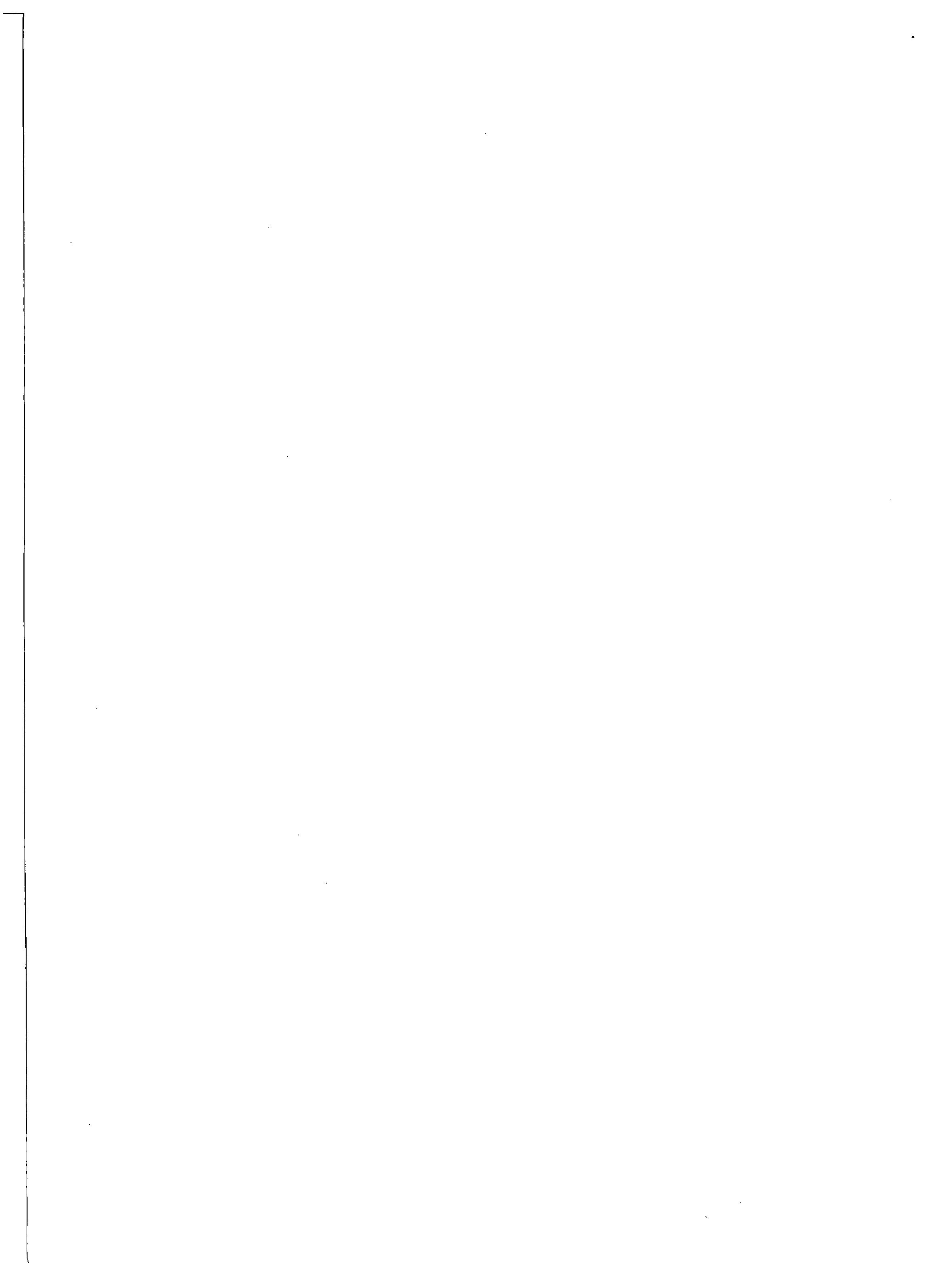


\section{LIST OF FIGURES}

\section{Figure}

1. Schematic of proposed process for using geothermal hot water to enhance conversion of lignocellulosic biomass to ethanol.

2. Quantity of reducing sugar extracted from autohydrolyzed wheat straw as a function of autohydrolysis time for runs at $180^{\circ} \mathrm{C}$ and various water/fiber weight ratios.

3. Production of reducing sugar during a standardized $3 \mathrm{hr}$ enzymatic hydrolysis of autohydrolyzed wheat straw as a function of autohydrolysis time for materials treated at $180^{\circ} \mathrm{C}$ and various water/fiber weight ratios.

4. Quantity of water soluble lignin extracted from autohydrolyzed wheat straw as a function of autohydrolysis time for runs at $180^{\circ} \mathrm{C}$ and various water/fiber weight ratios.

5. Quantity of reducing sugar extracted from autohydrolyzed wheat straw as a function of autohydrolysis time for runs in which the autohydrolysis charge contained phenol.

6. Production of reducing sugar during a standardized $3 \mathrm{hr}$ enzymatic hydrolysis of autohydrolyzed wheat straw as a function of autohydrolysis time for materials treated in the presence of phenol.

7. Effects of temperature and Lewis acid catalysis on the production of reducing sugar during the autohydrolysis of wheat straw.

8. Comparison of reducing sugar yields determined by analysis of raw and enzyme hydrolyzed extracts from wheat straw autohydrolyzed at $180^{\circ} \mathrm{C}$ and $155^{\circ} \mathrm{C}$.

9. Effects of temperature and Lewis acid catalysis on the production of water soluble lignin during autohydrolysis of wheat straw.

10. Effects of temperature and Lewis acid catalysis during autohydrolysis on the subsequent yield of reducing sugar in a standardized $3 \mathrm{hr}$ enzymatic hydrolysis of autohydrolyzed wheat straw.

11. Fractional conversion of cellulose during standard $3 \mathrm{hr}$ enzymatic hydrolysis of autohydrolyzed wheat straw as a function of autohydrolysis conditions.

12. Schematic of large-scale autohydrolysis apparatus. 
13. Reducing sugar concentration vs time for large-scale enzymatic hydrolysis of autohydrolyzed wheat straw.

14. Kinetics of baker's yeast fermentation of sugars obtained from large-scale enzymatic hydrolysis of autohydrolyzed wheat straw.

15. Effect of direct use of geothermal water on the yield of reducing sugar during the autohydrolysis of wheat straw at $180^{\circ} \mathrm{C} .44$

16. Effect of direct use of geothermal water in autohydrolysis of wheat straw at $180^{\circ} \mathrm{C}$ on the subsequent yield of reducing sugar during a standardized $3 \mathrm{hr}$ enzymatic hydrolysis.

17. Effect of direct use of geothermal water in extraction and washing procedures on the subsequent yield of reducing sugar during a standardized $3 \mathrm{hr}$ enzymatic hydrolysis of autohydrolyzed wheat straw. 


\section{INTRODUCTION}

Recently there has been much interest in developing processes for producing liquid fuels from renewable resources. The most logical long term approach in terms of economics derives the carbohydrate substrate for fermentation from the hydrolysis of cellulosic crop and forest residues rather than from grains or other high grade food materials $(1,2)$. Since the presence of lignin is the main barrier to the hydrolysis of cellulose from lignocellulosic materials, delignification processes developed by the wood pulping industry have been considered as possible prehydrolysis treatments. The delignification process under study in our laboratory is envisioned as a synthesis of two recently developed pulping processes. In the first step, called autohydrolysis, hot water is used directly to solubilize hemicellulose and to depolymerize lignin (3). Then, in a second step known as organosolv pulping (4), the autohydrolyzed material is extracted with aqueous alcohol.

As shown in Figure 1, this process can separate the original 1ignocellulosic material into three streams--hemicellulose in water, lignin in aqueous alcohol, and a cellulose pulp. Without further mechanical milling, delignified cellulose can be enzymatically hydrolyzed at $45-50^{\circ} \mathrm{C}$ to greater than $80 \%$ theoretical yield of glucose using fungal cellulases $(5,6)$. The resulting glucose syrup can then be fermented by yeast to produce ethanol or by selected bacteria to produce acetone and butanol or acetic and propionic acids (7).

One objection to such a process, however, is the large energy input that is required. In order to extend our supplies of liquid fuels and chemicals, it is important that the use of fossit 'fuels in any lignocellulosic conversion process be minimized. The direct use of geothermal hot water in carrying out the autohydrolysis and extraction operations, therefore, seems especially attractive. On the one hand, it facilitates the conversion of non-food biomass to fuels and 


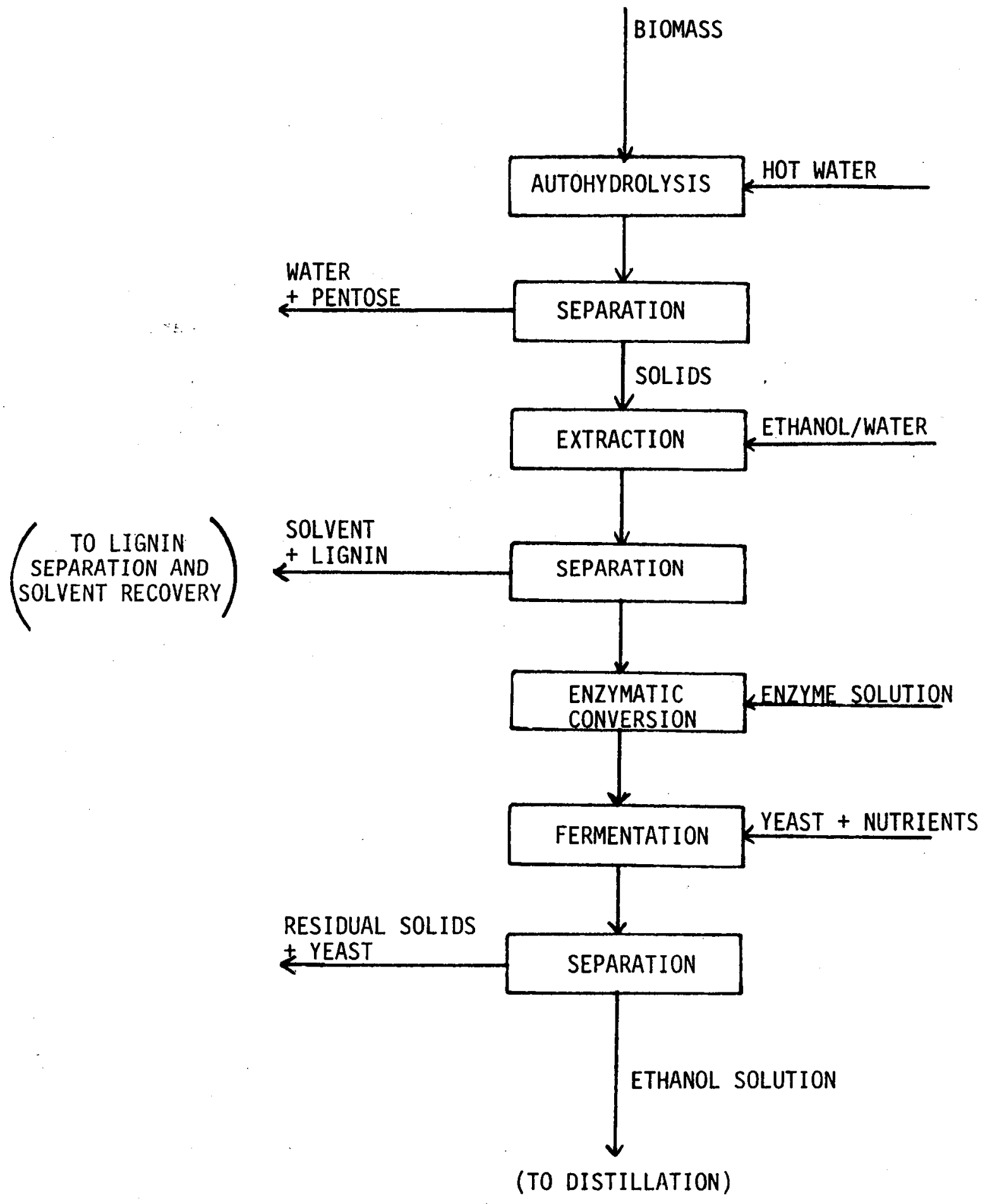

Figure 1. Schematic of proposed process for using geothermal hot water to enhance conversion of lignocellulosic biomass to ethanol. 
chemicals without wasting fossil fuel; and on the other hand, it provides a means for "exporting" geothermal energy from the well site.

The primary goal of the work discussed in this report was to investigate the effects of variations in autohydrolysis conditions on the production of fermentable sugars from wheat straw. In assessing the relative merits of various sets of conditions, we considered both the direct production of sugar from the autohydrolysis of hemicellulose and the subsequent yield from the enzymatic hydrolysis of cellulose. The principal parameters studied were time, temperature, and water/fiber weight ratio; however, we also investigated the effects of adding minor amounts of phenol and aluminum sulfate to the autohydrolysis charge. Phenol was selected for study because it was reported (8) to be effective in suppressing repolymerization of reactive lignin fragments. Aluminum sulfate, on the other hand, was chosen as a representative of the Lewis acids which, we hoped, would catalyze the delignification reactions.

Once optimal (or near optimal) autohydrolysis conditions were determined, we made a brief study of the effects of two major parameters, substrate concentration and enzyme/substrate ratio, on the sugar yield from enzymatic hydrolysis of optimally pretreated straw. In related experiments we characterized the efficiency with which these sugars could be fermented to ethanol. In most cases experiments were carried out using distilled water; however, in one important series the effects of direct use of geothermal water were determined for each of the major steps in the process shown in Figure 1.

An appendix to the body of the report describes the results of a preliminary economic evaluation of a plant designed to produce $25 \times 10^{6}$ gallons of ethanol per year from wheat straw using the best process conditions determined in the above work. Also appended are the results from a preliminary investigation of the 
applicability of autohydrolysis technology to the production of fermentable sugars from corn stover.

MATERIALS AND METHODS

\section{Reagents}

Wheat Straw. Locally obtained wheat straw was reduced in size so as to pass the 0.5 inch screen of a Fitz Model D Comminuter (Fitzpatrick Manufacturing Co., Elmhurst, Illinois). All procedures, including enzymatic hydrolysis, were carred out on this material without further size reduction.

Enzyme. Novo Laboratories, Inc., Wilton, Connecticut, generously supplied an experimental cellulase preparation (SP 122) from the submerged fermentation of the fungus Trichoderma reesei. This preparation contained 2.5 international $\mathrm{C}_{\mathrm{x}}$ units (substrate: CMC-4M6F; FMC Corp., Wilmington, Delaware) per gm and approximately 0.25 international $C_{1}$ units (substrate: Powder CC-31; Whatman, Inc., Clifton, New Jersey) per gm. Also provided was a cellobiase preparation $(250 \mathrm{~L})$ with a recommended usage level of $50 \%(\mathrm{w} / \mathrm{w})$ of the cellulase dose. Geothermal Water. The geothermal water used in this study was supplied by EG\&G Idaho, Inc., Idaho Falls, Idaho. This water was collected from well RRGP5 at the Raft River site on 8-21-79. A representative analysis of water from the Raft River site that was performed in 1976 indicated

$\begin{array}{lcc}\text { conductivity } & 2857 & \mu \mathrm{S} \\ \mathrm{pH} & 7.5 & \\ \mathrm{~F}^{-} & 6.2 & \mu \mathrm{g} / \mathrm{ml} \\ \mathrm{Cl}^{-} & 590 & \mu \mathrm{g} / \mathrm{ml} \\ \mathrm{SO}_{4}^{=} & 40 & \mu \mathrm{g} / \mathrm{ml} \\ \mathrm{alkalinity}^{-} & 40 & \mu \mathrm{g} / \mathrm{ml} \\ \mathrm{SiO}_{2} & 136 & \mu \mathrm{g} / \mathrm{ml}\end{array}$




$\begin{array}{lcc}\text { TDS } & 1482 & \mu \mathrm{g} / \mathrm{ml} \\ \mathrm{Mg} & 0.54 & \mu \mathrm{g} / \mathrm{m} 1 \\ \mathrm{Na} & 179 & \mu \mathrm{g} / \mathrm{ml} \\ \mathrm{Li} & 1.6 & \mu \mathrm{g} / \mathrm{m} 1 \\ \mathrm{Sr} & 1.2 & \mu \mathrm{g} / \mathrm{m} 1 \\ \mathrm{Ca} & 50 & \mu \mathrm{g} / \mathrm{m} 1 \\ \mathrm{~K} & 34 & \mu \mathrm{g} / \mathrm{m} 1\end{array}$

Procedures

The following procedures were routinely performed in the investigation of the effects of variations in autohydrolysis conditions on the production of fermentable sugars. Additional procedures and/or modifications of standard ones required in other phases of the work are described along with the results from these studies.

Autohydrolysis. Autohydrolysis was conducted in $35 \mathrm{ml}$ capacity bombs constructed from 4 × $3 / 4$ inch black iron pipe nipples fitted with a black iron cap at one end and a carbon steel Swagelok (Crawford Fitting Co., Solon, Ohio) cap fitting at the other end. Four bombs were also equipped with sealed thermocouples. In a typical run, fourteen bombs were identically loaded with $3.0 \mathrm{gm}$ (dry basis) of wheat straw and a predetermined quantity of water. In certain cases, a predetermined amount of phenol or aluminum sulfate was dissolved in the water. The bombs were then sealed and all placed at once in a silicone oil bath at a sufficiently high temperature to heat the contents of the bombs to the desired temperature in about 5-10 min. When the desired temperature was reached, timing was begun and two bombs were removed and placed-in a cold water bath. Additional pairs of bombs were then likewise removed and cooled over a 120 min period. Postautohydrolysis Extraction. Following autohydrolysis, free liquid was aspirated from the residual solids using a Buchner funnel equipped with a coarse 
fritted disc (Corning No. 36060; Fisher Scientific Co., St. Louis, Missouri). The solids were then suspended in $30 \mathrm{ml}$ of distilled water at ambient temperature $\left(20-25^{\circ} \mathrm{C}\right)$ for $10 \mathrm{~min}$. At the end of this extraction period, liquid was again aspirated from the solids, and the latter subjected to two on-filter washes with $15 \mathrm{~m} 1$ portions of distilled water at ambient temperature. The residual solids were then dried at $40^{\circ} \mathrm{C}$ for $48 \mathrm{hr}$ or more in preparation for enzymatic hydrolysis or fiber analysis. In addition, a portion of the combined filtrates was frozen for subsequent determination of extracted sugar and lignin. The extraction procedure was carried out using pure water at ambient temperature because earlier work (9) had shown that, in the case of wheat straw, this simple technique resulted in sugar yields equivalent to those obtained when extraction was performed with aqueous ethanol at $120-160^{\circ} \mathrm{C}$.

Enzymatic Hydrolysis of Extracted Sugars. In some cases, extracted sugars were hydrolyzed to monosaccharide form prior to being analyzed. For this procedure, equal volumes of extract and enzyme solution were mixed and then incubated in a water bath for $4 \mathrm{hr}$ at $50^{\circ} \mathrm{C}$. The enzyme solution contained $3.0 \mathrm{gm}$ SP 122 cellulase and $1.5 \mathrm{gm} 250 \mathrm{~L}$ cellobiase per $100 \mathrm{ml}$ citrate buffer $(0.1 \underline{\mathrm{M}}$, $\mathrm{pH}$ 4.8). Although primarily intended for use in cellulolytic applications, this enzyme preparation was shown to have significant hemicellulolytic activity as well.

Enzymatic Hydrolysis of Residual Solids. Approximately $100 \mathrm{mg}$ of predried solids was weighed into a $15 \mathrm{ml}$ plastic scintillation vial and wetted with 1.0 $\mathrm{ml}$ of citrate buffer $(0.1 \underline{\mathrm{M}}, \mathrm{pH} 4.8)$. When wetting was complete, $2.0 \mathrm{ml}$ of enzyme solution $(3.0 \mathrm{gm}$ SP 122 cellulase and $1.5 \mathrm{gm} 250 \mathrm{~L}$ cellobiase per $100 \mathrm{ml}$ citrate buffer) was added, and the mixture incubated in a rotary shaker at $50^{\circ} \mathrm{C}$. After $3 \mathrm{hr}$ of incubation, $1.5 \mathrm{ml}$ of the mixture was drawn off and centrifuged at $16,000 \mathrm{x}$ for $4 \mathrm{~min}$. The supernatant liquid was then frozen for subsequent 
analysis of reducing sugar. In order to determine the amount of endogenous sugar that was simply extracted from the wheat straw solids, each sample was paired with a control incubated with $3.0 \mathrm{ml}$ of citrate buffer containing no enzymes.

Analytical Methods

Reducing Sugar Analysis. Total reducing sugar was assayed by reaction with 3,5-dinitrosalicylic acid (DNSA) using the method described by Miller (10). The procedure was calibrated with standard solutions of glucose; hence, the reducing sugar was determined as $\mathrm{mg}$ apparent glucose.

HPLC Analysis of Sugars and Sugar Degradation Products. A high performance liquid chromatograph (Model ALC-201; Waters Associates, Milford, Massachusetts) equipped with a differential refractometer detector was used to analyze for selected monosaccharides and their degradation products. The species of interest were D-glucose, D-galactose, D-mannose, D-fructose, D-xylose, L-arabinose, 5-hydroxymethylfurfural (HMF) and 2-furfuraldehyde (FA). The latter compounds, HMF and FA, were thought to be the principal degradation products of the hexoses and pentoses, respectively. Separation was accomplished on an ion exchange column (Model HPX-85; Biorad Laboratories, Richmond, California) operated at $85^{\circ} \mathrm{C}$ with distilled water as the mobile phase. During an analysis, the flow rate was initially set at $0.6 \mathrm{ml} / \mathrm{min}$ and then increased to $1.6 \mathrm{ml} / \mathrm{min}$ at $17 \mathrm{~min}$ in order to hasten elution of the strongly retained degradation products. With this procedure, an entire analysis took about $28 \mathrm{~min}$, with good resolution obtained for all compounds except mannose and fructose which coeluted. Soluble Lignin Analysis. Lignin depolymerization products were assayed by the Pear1-Benson nitrosylation method (11). Guaiacol (2-methoxyphenol) was used as a standard; therefore, the soluble lignin was determined as $\mathrm{mg}$ apparent guaiaco1. 
Fiber Analysis. Predried samples of wheat straw solids were ground to 40 mesh in a wiley mill and then redried at $65^{\circ} \mathrm{C}$ overnight. Portions of this material were then analyzed for hemicellulose, cellulose and lignin according to methods described by van Soest and wine (12) and Goering and van Soest (13). Hemicellulose was determined from the difference between neutral detergent fiber (NDF) and acid detergent fiber (ADF); lignin was determined by permanganate oxidation of $\mathrm{ADF}$; and cellulose was determined from the weight loss upon ashing lignin-free ADF.

RESULTS AND DISCUSSION

\section{Autohydrolysis Studies}

Effects of Water/Fiber Ratio. Figures 2-4 show the results obtained from a series of autohydrolysis experiments conducted at $180^{\circ} \mathrm{C}$ and a water/fiber weight ratio (W/F) ranging from $1 / 1$ to 10/1. From Figure 2 it is clear that in all cases the maximum amount of extractable reducing sugar was obtained at autohydrolysis times of 20-35 min. The lower recoveries at longer times were probably due to conversion of sugars to furfural and related compounds. The rate of sugar production (as judged by the rising portions of the curves) appeared to be significantly lower at $W / F=1 / 1$. We suspect that this result was due to incomplete wetting of the wheat straw during autohydrolysis, since visual inspection of this autohydrolyzed material did not reveal the uniform darkening observed at higher W/F ratios.

Figure 3 shows the yields of reducing sugar obtained from the enzymatic hydrolysis of samples of the autohydrolyzed materials. For all W/F ratios the curves tended to plateau at autohydrolysis times around $35 \mathrm{~min}$, which was about the point at which the net production of reducing sugar from autohydrolysis of hemicellulose reached a maximum. It should also be noted that significantly lower yields were again realized with material autohydrolyzed at $W / F=1 / 1$. We 


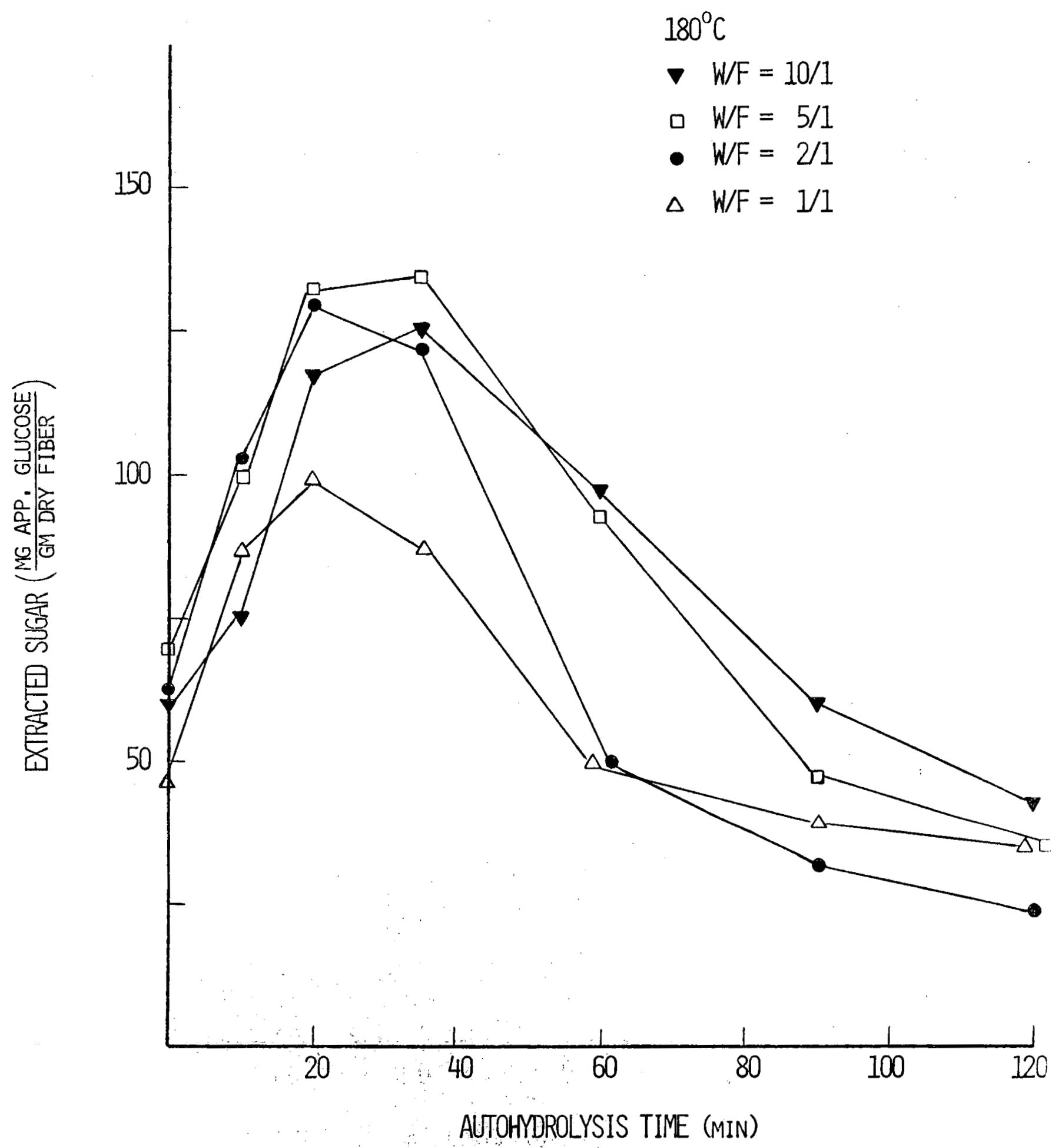

Figure 2. Quantity of reducing sugar extracted from autohydrolyzed wheat straw as a function of autohydrolys is time for runs at $180^{\circ} \mathrm{C}$ and various water/fiber (W/F) weight ratios. Yield is based on the original dry weight of the straw. 


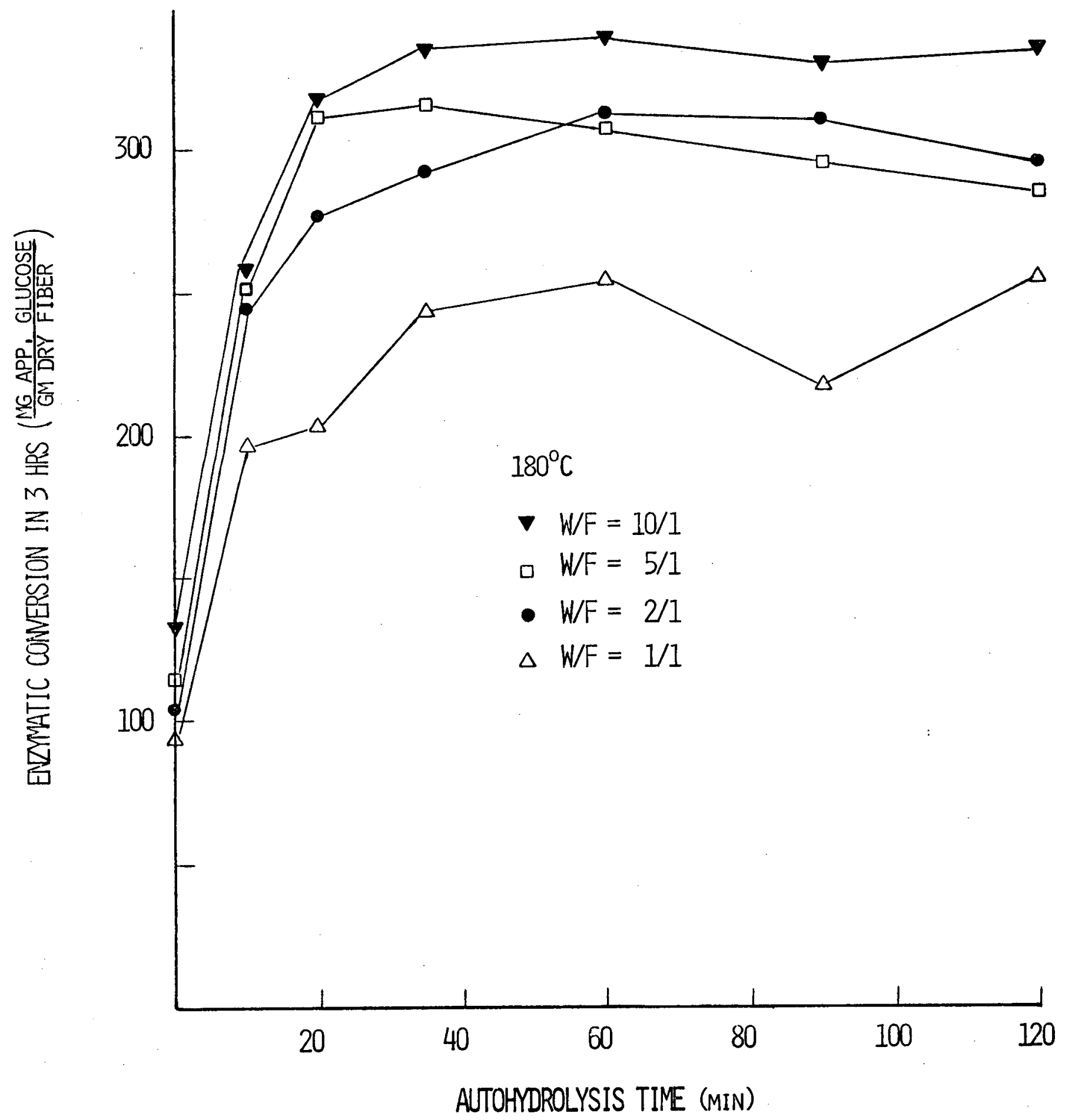

Figure 3. Production of reducing sugar during a standardized $3 \mathrm{hr}$ enzymatic hydrolys is of autohydrolyzed wheat straw as a function of autohydrolysis time for materials treated at $180^{\circ} \mathrm{C}$ and various water/fiber (W/F) weight ratios. Yield is based on the dry weight of the autohydrolyzed straw. 


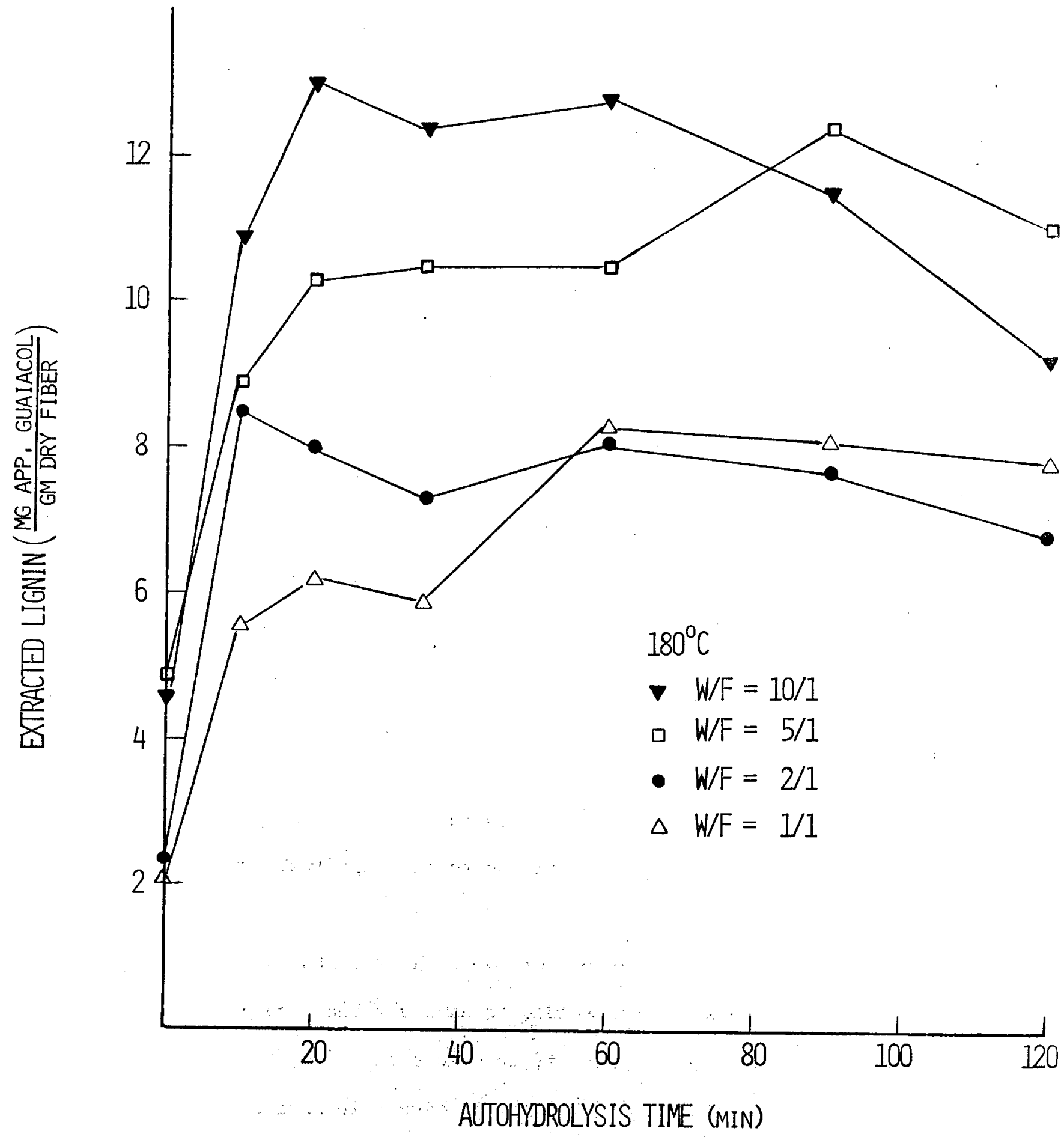

Figure 4. Quantity of water soluble lignin extracted from autohydrolyzed wheat straw as a function of autohydrolys is time for runs at $180^{\circ} \mathrm{C}$ and various water/fiber (W/F) weight ratios. Yield is based on the original dry weight of the straw. 
interpret these results to mean that the removal of hemicellulose via autohydrolysis was a major factor in exposing cellulose fibers to enzymatic attack.

As shown in Figure 4, the amount of soluble lignin extracted from the autohydrolyzed wheat straw also tended to reach a plateau with increasing autohydrolysis time. However, despite the qualitative similarity in the shapes of the sets of curves shown in Figures 3 and 4, there does not seem to be any simple quantitative relation between the amount of lignin extracted and the conversion achieved in the enzymatic hydrolysis. This is most evident at longer autohydrolysis times. Note, for example, that in this region the curves for $W / F=1 / 1$ and $W / F=2 / 1$ are nearly coincident in Figure 4 but quite widely separated in Figure 3.

Effects of Added Phenol. Figures 5 and 6 present some of the results obtained from experiments in which minor amounts of phenol were added to the autohydrolysis charge. Compared to the control run (no phenol added), the addition of 0.2 parts phenol per 100 parts wheat straw appeared to increase both the maximum in the extracted sugar curve (Figure 5) and the plateau in the enzymatic conversion curve (Figure 6). Essentially equivalent results (not shown in Figures 5 and 6) were obtained in a run with 2.0 parts pheno1 per 100 parts wheat straw. It should be noted, however, that the comparison of the peak values in Figure 5 may not be justified due to the relatively wide gaps between sampling times.

As noted before, the motivation for these experiments was a report (8) that aromatic compounds such as phenol tended to suppress the repolymerization of lignin fragments. We reasoned that, if this were the case, then the addition of phenol to the autohydrolysis charge should result in greater extraction of soluble lignin and, consequently, higher levels of enzymatic hydrolysis. The data shown in Figure 6 are consistent with this hypothesis. However, we were 


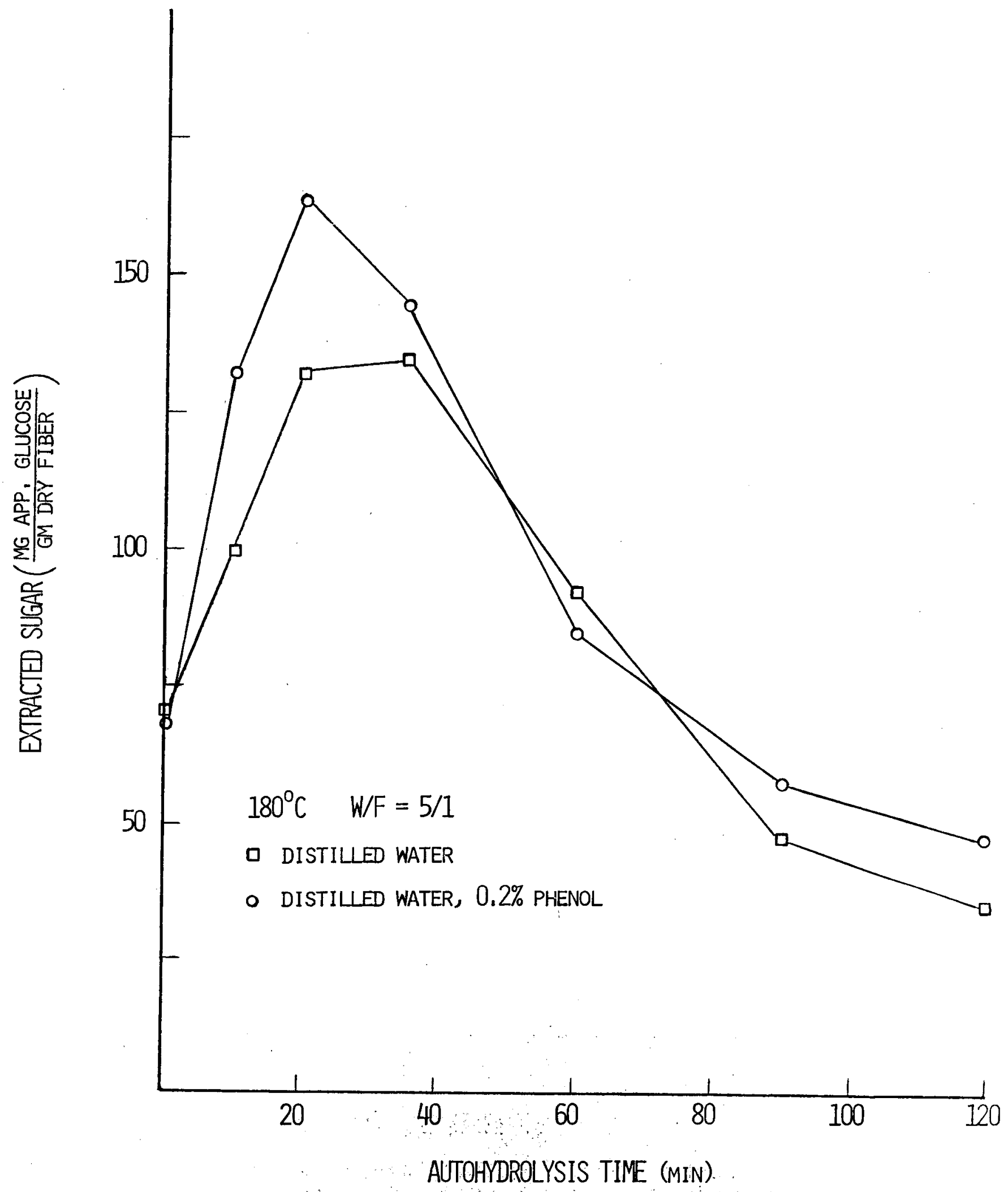

Figure 5. Quantity of reducing sugar extracted from autohydrolyzed wheat straw as a function of autohydrolys is time for runs in which the autohydrolys is charge contained phenol. All runs were conducted at $180^{\circ} \mathrm{C}$ and a water/fiber (W/F) weight ratio of $5 / 1$. Sugar yield and phenol addition are based on the original dry weight of the straw. 


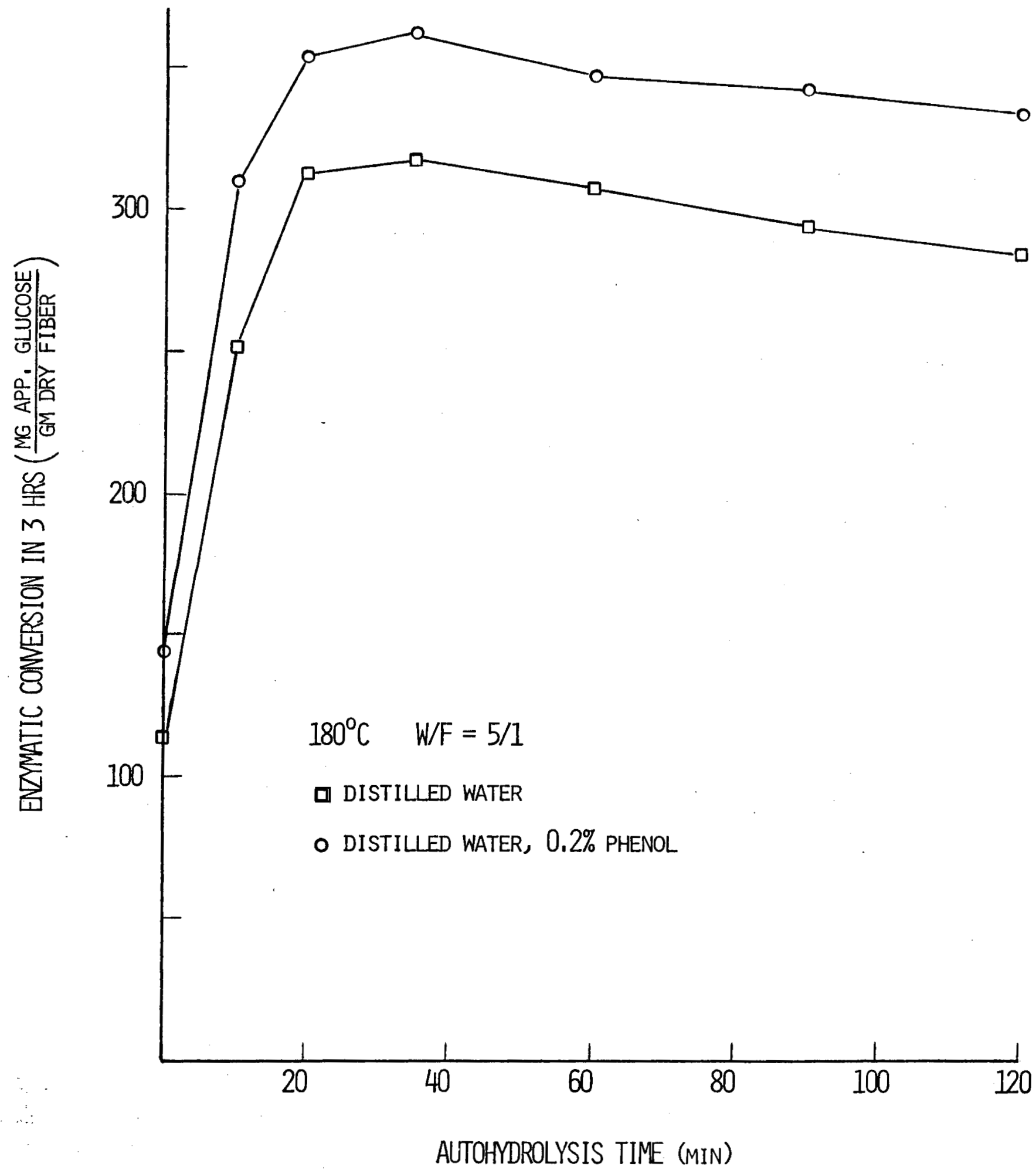

Figure 6. Production of reducing sugar during a standardized $3 \mathrm{hr}$ enzymatic hydrolysis of autohydrolyzed wheat straw as a function of autohydrolys is time for materials treated in the presence of phenol. Autohydrolys is was conducted at $180^{\circ} \mathrm{C}$ and a water/fiber (W/F) weight ratio of $5 / 1$. Phenol addition is based on the original dry weight of the straw. Sugar yield is based on the dry weight of the autohydrolyzed straw. 
not able to directly verify that the presence of phenol during autohydrolysis enhanced the extraction of soluble lignin because phenol was found to interfere with the Pearl-Benson assay (11) for soluble lignin.

Effects of Temperature and Added Aluminum Sulfate. All results presented thus far were obtained from experiments in which autohydrolysis was carried out at $180^{\circ} \mathrm{C}$. Since only about $10-12 \%$ of the identified geothermal sources in the United States are capable of delivering water at $180^{\circ} \mathrm{C}(14)$, we decided to investigate the possibility of employing a lower temperature for the autohydrolysis operation. In this series of experiments we also studied the effects of adding aluminum sulfate to the autohydrolysis charge. The reasoning here was that the addition of a Lewis acid catalyst might compensate for the lower reaction temperature. A1l experiments were conducted with $\mathrm{W} / \mathrm{F}=5 / 1$ during autohydrolysis.

Figure 7 shows the quantity of reducing sugar extracted from the autohydrolyzed wheat straw as a function of autohydrolysis time in each run. In this case, sugars were hydrolyzed to monomeric form prior to analysis by incubating the extracts with a hydrolytic enzyme solution for $4 \mathrm{hr}$ at $50^{\circ} \mathrm{C}$. From these data it can be seen that both the rate of saccharification (presumably of hemicellulose) and the rate of sugar degradation increased markedly with increasing temperature. The competing effects of production and degradation of sugars can most easily be seen in the curves for the two runs at $180^{\circ} \mathrm{C}$ which exhibit sharp maxima. It is also important to note that at any given temperature the rate of sugar production was higher when aluminum sulfate was present. Moreover, if the curves for the two runs at $155^{\circ} \mathrm{C}$ are compared, it is apparent that aluminum sulfate catalyzed only the saccharification reactions and not the sugar degradation reactions. As a result, comparable high yields of reducing sugar (250$260 \mathrm{mg}$ per gm dry fiber) were obtained at relatively short autohydrolysis times 


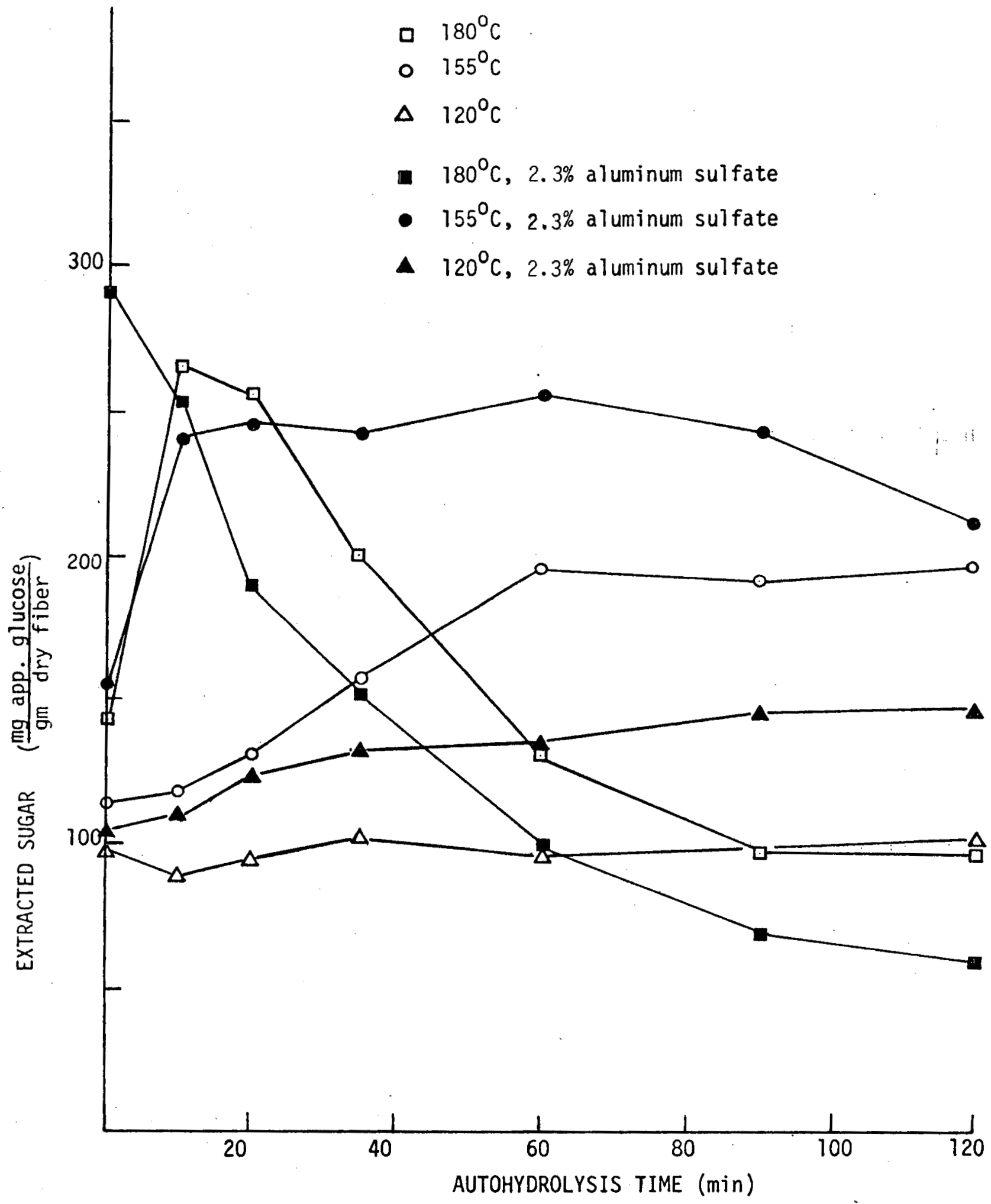

Figure 7. Effects of temperature and Lewis acid catalysis on the production of reducing sugar during the autohydralys is of wheat straw. In a11 cases the water/fiber weight ratio during autohydrolys is was 5/1. Aluminum sulfate addition and sugar yield are based on the original dry weight of the straw. Sugars were enzymatically hydrolyzed to monosaccharides prior to assay. 
(10-20 min) in the catalyzed run at $155^{\circ} \mathrm{C}$ and the uncatalyzed run at $180^{\circ} \mathrm{C}$. Also important from an engineering viewpoint is that in the former case the sugar yield reached a plateau rather than a sharp peak, thereby simplifying the process control strategy required for a high sugar yield.

As noted above, the reducing sugar yields depicted in Figure 7 were derived from analyses of enzyme hydrolyzed extracts. Figures $8 \mathrm{a}$ and $8 \mathrm{~b}$ compare the results obtained from analysis of hydrolyzed and unhydrolyzed extracts for the uncatalyzed runs at $180^{\circ} \mathrm{C}$ and $155^{\circ} \mathrm{C}$, respectively. In the latter case, the ratio of the two values (which yields an apparent degree of polymerization) was fairly constant at $1.7-1.9$. At $180^{\circ} \mathrm{C}$, however, the ratio declined from 1.8 at 0 min to 1.2 at $30 \mathrm{~min}$ and then remained approximately constant. In general, the addition of aluminum sulfate resulted in lower values for the apparent degree of polymerization, which again indicates the apparent catalysis of hydrolytic reactions by this Lewis acid. It is clear from these data that autohydrolysis does not proceed by an unzipping mechanism, but rather by a more or less random cleavage of polysaccharide chains. It is also apparent that simply analyzing the raw extract for reducing sugar groups can, in some cases, significantly underestimate the actual quantity of sugar produced.

To gain additional information on the composition of the sugars produced during autohydrolysis, samples of the raw extracts were analyzed by means of high performance liquid chromatography (HPLC). The principal results derived from these analyses are presented in Table 1 through Table 6 . These tables list a combined total for mannose and fructose because these sugars coelute in the procedure employed. However, since wheat is known (15) to store carbohydrates in the form of fructosans (polymers of fructose containing a terminal glucose unit), we believe that fructose comprised the bulk of this total. In the discussion that follows, therefore, this total is assigned to fructose alone. 

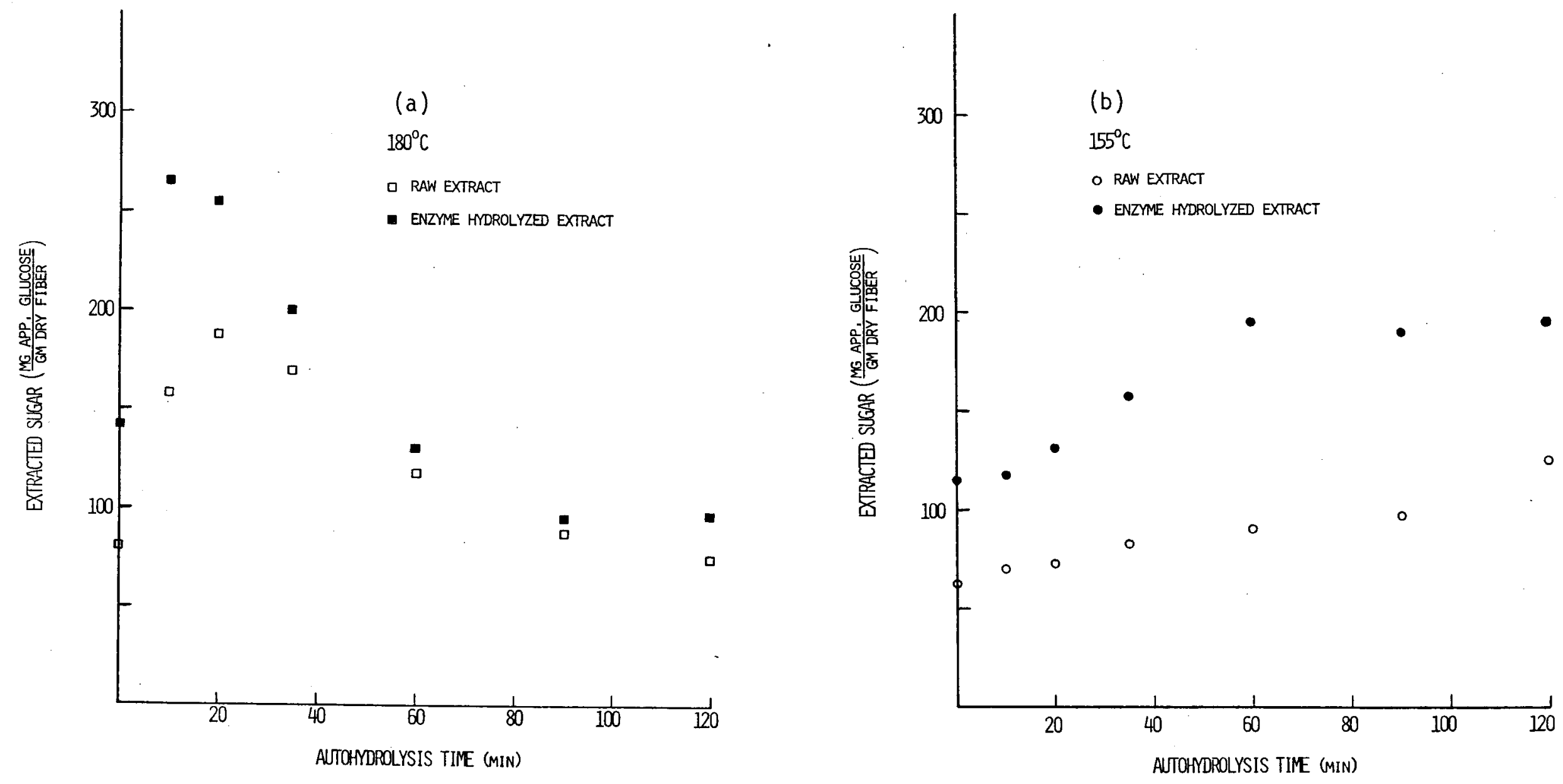

Figure 8. Comparison of reducing sugar yields determined by analysis of raw and enzyme hydrolyzed extracts from wheat straw autohydrolyzed at (a) $180^{\circ} \mathrm{C}$ and (b) $155^{\circ} \mathrm{C}$. In both cases the water/fiber weight ratio during autohydrolysis was $5 / 1$ and the water contained no aluminum sulfate. Sugar yield is based on the original dry weight of the straw. 
Table 1. Yields of some sugars and sugar degradation products during autohydrolysis of wheat straw at $120^{\circ} \mathrm{C}{ }^{\mathrm{a}}$, b.

\begin{tabular}{|c|c|c|c|c|c|c|c|}
\hline \multirow[b]{2}{*}{ Compound } & \multicolumn{7}{|c|}{ Autohydrolysis Time (min) } \\
\hline & 0 & 10 & 20 & 35 & 60 & 90 & 120 \\
\hline Glucose & 20 & 18 & 19 & 29 & 22 & 20 & 19 \\
\hline Fructose + Mannose & 31 & 31 & 33 & 33 & 35 & 31 & 26 \\
\hline 5-Hydroxymethylfurfural (HMF) & 0 & 0 & 0 & 0 & 0 & 0 & 0 \\
\hline Arabinose & 0 & 0 & 0 & 0 & 0 & 0 & 0 \\
\hline Xylose & 0 & 0 & 0 & 0 & 0 & 0 & 0 \\
\hline 2-Furfuraldehyde (FA) & 0 & 0 & 0 & 0 & 0 & 0 & 0 \\
\hline
\end{tabular}

${ }^{a}$ Compounds were determined by means of high performance liquid chromatography and expressed as mg per gm based on the original dry weight of straw.

${ }^{b}$ Autohydrolysis was conducted at a water/fiber weight ratio of $5 / 1$.

Table 2. Yields of some sugars and sugar degradation products during autohydrolysis of wheat straw at $120^{\circ} \mathrm{C}$ in the presence of aluminum sulfate. ${ }^{\mathrm{a}, \mathrm{b}}$

\begin{tabular}{|c|c|c|c|c|c|c|c|}
\hline \multirow[b]{2}{*}{ Compound } & \multicolumn{7}{|c|}{ Autohydrolysis Time (min) } \\
\hline & 0 & 10 & 20 & 35 & 60 & 90 & 120 \\
\hline Glucose & 21 & 25 & 27 & 29 & 33 & 34 & 36 \\
\hline Fructose + Mannose & 42 & 53 & 51 & 51 & 55 & 54 & 49 \\
\hline 5-Hydroxymethylfurfural (HMF) & 0 & 0 & 0 & 0 & 0 & 0 & 0 \\
\hline Arabinose & 0 & 0 & 0 & 9 & 11 & 15 & 16 \\
\hline Xylose & 0 & 0 & 0 & 0.4 & 0.6 & 0.8 & 1.0 \\
\hline 2-Furfuraldehyde (FA) & 0 & 0 & 0 & 0 & 0 & 0.5 & 1.4 \\
\hline
\end{tabular}

${ }^{a}$ Compounds were determined by means of high performance liquid chromatography and expressed as mg per gm based on the original dry weight of straw.

${ }^{b}$ Autohydrolysis was conducted at a water/fiber weight ratio of $5 / 1$. Concentration of aluminum sulfate wăs $2.3 \%(w / w)$ based on the original dry weight of straw. 
Table 3. Yields of some sugars and sugar degradation products during autohydrolysis of wheat straw at $155^{\circ} \mathrm{C}$. a, b

\begin{tabular}{|c|c|c|c|c|c|c|c|}
\hline \multirow[b]{2}{*}{ Compound } & \multicolumn{7}{|c|}{ Autohydrolysis Time (min) } \\
\hline & 0 & 10 & 20 & 35 & 60 & 90 & 120 \\
\hline Glucose & 22 & 28 & 28 & 25 & 21 & 20 & 18 \\
\hline Fructose + Mannose & 28 & 25 & 25 & 19 & 14 & 9 & 7 \\
\hline 5-Hydroxymethy 1 furfural (HMF) & 0 & 0 & 0 & 0 & 1.0 & 3.2 & 2.6 \\
\hline Arabinose & 0 & 1.4 & 6.3 & 7.4 & 9.6 & 11 & 12 \\
\hline Xylose & 0 & 0.3 & 0.7 & 0.7 & 1.2 & 3.6 & 6.8 \\
\hline 2-Furfuraldeyde (FA) & 0 & 0 & 0 & 0 & 4.7 & 5.9 & 5.7 \\
\hline
\end{tabular}

${ }^{a}$ Compounds were determined by means of high performance liquid chromatography and expressed as $\mathrm{mg}$ per gm based on the original dry weight of straw.

${ }^{b}$ Autohydrolysis was conducted at a water/fiber weight ratio of $5 / 1$.

Table 4. Yields of some sugars and sugar degradation products during autohydrolysis of wheat straw at $155^{\circ} \mathrm{C}$ in the presence of aluminum sulfate. ${ }^{a}, \mathrm{~b}$

\begin{tabular}{|c|c|c|c|c|c|c|c|}
\hline \multirow[b]{2}{*}{ Compound } & \multicolumn{7}{|c|}{ Autohydrolysis Time (min) } \\
\hline & 0 & 10 & 20 & 35 & 60 & 90 & 120 \\
\hline Glucose & 25 & 29 & 28 & 21 & 19 & 18 & 19 \\
\hline Fructose + Mannose & 48 & 37 & 30 & 20 & 13 & 9 & 11 \\
\hline 5-Hydroxymethylfurfural (HMF) & 0 & 0 & 0 & 3.4 & 4.3 & 13 & 18 \\
\hline Arabinose & 8.9 & 13 & 14 & 12 & 8.5 & 6.6 & 5.7 \\
\hline Xylose & 1.3 & 14 & 21 & 20 & 20 & 20 & 25 \\
\hline 2-Furfuraldehyde (FA) & 0.6 & 1.7 & 3.5 & 4.3 & 6.9 & 11 & 13 \\
\hline
\end{tabular}

Compounds were determined by means of high performance liquic chromatography and expressed as $\mathrm{mg}$ per gm based on the original dry weight of straw.

${ }^{b}$ Autohydrolysis was conducted at a water/fiber weight ratio of $5 / 1$. Concentration of aluminum sulfate was $2.3 \%(\mathrm{w} / \mathrm{w})$ based on the original dry weight of straw. 
Table 5. Yields of some sugars and sugar degradation products during autohydrolysis of wheat straw at $180^{\circ} \mathrm{C}$. a,b

\begin{tabular}{|c|c|c|c|c|c|c|c|}
\hline \multirow[b]{2}{*}{ Compound } & \multicolumn{7}{|c|}{ Autohydrolysis Time (min) } \\
\hline & 0 & 10 & 20 & 35 & 60 & 90 & 120 \\
\hline Glucose & 19 & 13 & 10 & 13 & 12 & 10 & 9 \\
\hline Fructose + Mannose & 16 & 5.3 & 5.8 & 2.5 & 1.0 & 1.1 & 0 \\
\hline 5-Hydroxymethylfurfural (HMF) & 0 & 2.3 & 12 & 33 & 34 & 31 & 32 \\
\hline Arabinose & 7.2 & 10 & 7.5 & 3.2 & 0.2 & 0 & 0 \\
\hline Xylose & 3.1 & 5.6 & 16 & 27 & 17 & 8.7 & 4.1 \\
\hline 2-Furfuraldehyde (FA) & 0.8 & 6.9 & 10 & 11 & 11 & 11 & 14 \\
\hline
\end{tabular}

${ }^{a}$ Compounds were determined by means of high performance liquid chromatography and expressed as $\mathrm{mg}$ per gm based on the original dry weight of straw.

${ }^{b}$ Autohydrolysis was conducted at a water/fiber weight ratio of $5 / 1$.

Table 6. Yields of some sugars and sugar degradation products during autohydrolysis of wheat straw at $180^{\circ} \mathrm{C}$ in the presence of aluminum sulfate. ${ }^{\mathrm{a}, \mathrm{b}}$

\begin{tabular}{lcccccccc}
\hline & \multicolumn{7}{c}{ Autohydrolysis Time (min) } \\
Compound & 0 & 10 & 20 & 35 & 60 & 90 & 120 \\
& & & & & & & & \\
& & 27 & 20 & 20 & 12 & 5.4 & 3.0 & 1.0 \\
Glucose & 28 & 16 & 11 & 2.2 & 1.6 & 0 & 0 \\
Fructose + Mannose & 0.9 & 8.6 & 21 & 17 & 12 & 11 & 11 \\
$\begin{array}{l}\text { 5-Hydroxymethylfurfural (HMF) } \\
\text { Arabinose }\end{array}$ & 17 & 9.4 & 5.6 & 2.1 & 1.3 & 0 & 0 \\
$\begin{array}{l}\text { Xylose } \\
\text { 2-Furfuraldehyde (FA) }\end{array}$ & 27 & 33 & 25 & 8.2 & 2.4 & 1.5 & 0.6 \\
& 2.6 & 9.7 & 13 & 14 & 13 & 14 & 14 \\
\hline
\end{tabular}

${ }^{a}$ Compounds were determined by means of high performance liquid chromatography and expressed as mg per gm based on the original dry: weight of straw.

${ }^{b}$ Autohydrolysis was conducted at a water/fiber weight ratio of $5 / 1$. Concentration of aluminum sulfate was $2.3 \%(\mathrm{w} / \mathrm{w})$ based on the original dry weight of straw. 
In the uncatalyzed run at $120^{\circ} \mathrm{C}$ (see Table 1), the only monosaccharides present in detectable amounts were glucose and fructose, with their yields being relatively insensitive to reaction time. In the catalyzed run (see Table 2), these sugars were again predominant, but some arabinose and traces of xylose were also found at reaction times of $35 \mathrm{~min}$ or more. In addition, the yield of glucose, instead of remaining constant, seemed to increase with time. There was little evidence of sugar degradation at $120^{\circ} \mathrm{C}$, regardless of whether catalyst was present or not.

At $155^{\circ} \mathrm{C}$ (see Tables 3 and 4 ), the effects of sugar degradation reactions were more apparent. In both the catalyzed and uncatalyzed cases, the hexose sugar yields reached peak values early in the run and then declined, with fructose peaking earlier and then declining more rapidly than glucose. It is to be noted, however, that the first appearance of HMF, the supposed product of hexose degradation, occurred some time after the decreases in hexose yields were first observed and that the final yield of HMF was insufficient to account for the decreases in glucose and fructose from their peak values. Both the production and degradation of pentoses were more evident at $155^{\circ} \mathrm{C}$ than at $120^{\circ} \mathrm{C}$. In the uncatalyzed run, the yields of arabinose and xylose both increased steadily, but the former began to level off after $60 \mathrm{~min}$, which was about the time that FA first appeared. In the catalyzed run, the yield of xylose was greatly increased; however, arabinose peaked at a reaction time of $20 \mathrm{~min}$ and then declined to levels lower than those observed in the uncatalyzed run. Consistent with the loss of arabinose was the increased yield of FA in the catalyzed run. In the runs at $180^{\circ} \mathrm{C}$ (see Tables 5 and 6 ), the hexose yields apparent1y peaked during the heat-up stage and then declined throughout the two-hour sampling period. As at $155^{\circ} \mathrm{C}$, fructose degradation appeared to be more rapid. A curious feature of these results is that in the catalyzed run the yield of HMF peaked 
at a reaction time of $20 \mathrm{~min}$ and then declined despite the fact that glucose and fructose continued to degrade. Pentose yields peaked early in the runs and then declined. For both arabinose and xylose the peak was higher and occurred earlier in the catalyzed run. In neither run was the observed yield of FA sufficient to account for the decreases in the pentoses from their peak values. This is especially noticeable in the catalyzed run, where the yield of FA remained constant after 20 min while the quantity of xylose declined from $25 \mathrm{mg} / \mathrm{gm}$ to less than $1.0 \mathrm{mg} / \mathrm{gm}$.

In general, the HPLC analyses suggest the following conclusions:

- There are at least two polymeric sources of the sugar produced during autohydrolysis, fructosans which give rise to glucose and fructose and arabinoxylans which give rise to arabinose and xylose.

- Fructosans are converted to monomeric sugars even at $120^{\circ} \mathrm{C}$, but higher temperatures are required for hydrolysis of arabinoxylans.

- Fructose linkages appear more susceptible to hydrolysis than glucose linkages; likewise, arabinose linkages seem more susceptible than xylose linkages.

- At all temperatures, hydrolysis reactions appear to be promoted by the presence of aluminum sulfate.

- Significant degradation of both hexose and pentose monomers occurs at $155^{\circ} \mathrm{C}$ and higher.

- Products other than HMF and FÁ must result from the degradation of sugars, or these species must be subject to further reaction. Another point worth mentioning is that in the runs at $1.55^{\circ} \mathrm{C}$ and $180^{\circ} \mathrm{C}$ the combined yields of the monomeric sugars assayed by HPLC were considerably less than the total reducing, sugar values obtained from the DNSA analyses. This suggests that much of reducing sugar resulting from hydrolysis of hemicellulose remains in oligomeric form. 
Table 7 shows the variation in the composition of residual wheat straw solids as a function of autohydrolysis conditions. The data indicate that the loss of hemicellulose increased with increasing temperature and, at any given temperature, with the addition of aluminum sulfate. The pattern is consistent with the hypothesis that the sugars present after autohydrolysis at $120^{\circ} \mathrm{C}$ were primarily derived from fructosans (which would assay as "cell solubles" in the fiber analysis); whereas, the sugars obtained at higher temperatures contained an increasing fraction derived from arabinoxylans (which would assay as "hemicellulose" in the fiber analysis). Such an interpretation can also be shown to be consistent with the cellulose percentages given in Table 7 . If negligible decomposition of cellulose occurs, then the cellulose percentage should increase in a manner related to the decrease in the hemicellulose percentage. This was indeed the case for the materials treated at 120 and $155^{\circ} \mathrm{C}$. For the samples autohydrolyzed at $180^{\circ} \mathrm{C}$, however, the cellulose percentage peaked at about the time the hemicellulose percentage fell to zero and thereafter decreased. We believe that this decrease in the cellulose percentage at longer treatment times, as well as the concomitant artifactual (negative) percentages for hemicellulose, were caused by condensation of sugar decomposition products with lignin. This view is supported by the apparent sharp increase in lignin percentage at the longer treatment times and by the unexpectedly low recoveries of HMF and FA in the extracts (see Tables 5 and 6 and related discussion).

The amount of lignin extracted from autohydrolyzed wheat straw is shown as a function of autohydrolysis conditions in Figure 9. It is clear that the rate of production of soluble lignin increased with increasing temperature. In addition, the initial rate of production at any given temperature appeared to be greater when aluminum sulfate was present. These same general observations were made in discussing the extraction of reducing sugar; however, a comparison 
Table 7. Effect of Autohydrolysis on Composition of Wheat Straw. Hemicellulose Content (wt \%)

\begin{tabular}{|c|c|c|c|c|c|c|}
\hline Autohydrolysis & & & ydro & is Ti & $\min )$ & \\
\hline Conditions & 0 & 10 & 20 & 35 & 60 & 120 \\
\hline $120^{\circ} \mathrm{C}$, No Catalyst & 28.5 & -- & -- & - & 27.5 & 25.2 \\
\hline $120^{\circ} \mathrm{C}, 2.3 \%$ Catalyst & 25.2 & - & -- & -- & 25.1 & 21.7 \\
\hline $155^{\circ} \mathrm{C}$, No Catalyst & 27.9 & 27.9 & 22.7 & 17.8 & 13.4 & -- \\
\hline $155^{\circ} \mathrm{C}, 2.3 \%$ Catalyst & 24.3 & 16.6 & 16.9 & 5.6 & 2.9 & -- \\
\hline $180^{\circ} \mathrm{C}$, No Catalyst & 23.0 & 1.6 & -2.4 & -6.5 & -7.0 & -- \\
\hline $180^{\circ} \mathrm{C}, 2.3 \%$ Catalyst & 4.4 & 1.9 & -- & -5.3 & -5.7 & -- \\
\hline
\end{tabular}

Cellulose Content (wt \%)

\begin{tabular}{lcccccc}
\hline $\begin{array}{l}\text { Autahydrolysis } \\
\text { Conditions }\end{array}$ & 0 & \multicolumn{5}{c}{ Autohysrolysis Time $(\mathrm{min})$} \\
\hline $120^{\circ} \mathrm{C}$, No Catalyst & 40.5 & - & -- & -- & 42.0 & 41.2 \\
$120^{\circ} \mathrm{C}, 2.3 \%$ Catalyst & 40.6 & -- & -- & -- & 40.1 & 41.6 \\
$155^{\circ} \mathrm{C}$, No Catalyst & 40.5 & 40.8 & 44.2 & 45.0 & 47.3 & -- \\
$155^{\circ} \mathrm{C}, 2.3 \%$ Catalyst & 41.6 & 42.3 & 49.2 & 52.3 & 52.3 & -- \\
$180^{\circ} \mathrm{C}$, No Catalyst & 42.5 & 58.2 & 56.7 & 53.6 & 50.6 & -- \\
$180^{\circ} \mathrm{C}, 2.3 \%$ Catalyst & 52.7 & 56.7 & -- & 50.8 & 48.1 & -- \\
\hline
\end{tabular}

Lignin Content (wt \%)

\begin{tabular}{lcccccc}
\hline $\begin{array}{l}\text { Autohydrolysis } \\
\text { Conditions }\end{array}$ & 0 & 10 & 20 & 35 & 60 & 120 \\
\hline $120^{\circ} \mathrm{C}$, No Catalyst & 11.9 & -- & -- & -- & 13.0 & 11.7 \\
$120^{\circ} \mathrm{C}, 2.3 \%$ Catalyst & 13.5 & -- & -- & -- & 10.7 & 10.5 \\
& & & & & & \\
$155^{\circ} \mathrm{C}$, No Catalyst & 11.5 & 11.7 & 13.2 & 11.9 & 13.2 & -- \\
$155^{\circ} \mathrm{C}, 2.3 \%$ Catalyst & 11.4 & 13.7 & 10.9 & 13.0 & 14.7 & -- \\
$180^{\circ} \mathrm{C}$, No Catalyst & 10.0 & 13.2 & 12.4 & 17.5 & 21.0 & -- \\
$180^{\circ} \mathrm{C}, 2.3 \%$ Catalyst & 11.7 & 12.9 & -- & 21.1 & 25.0 & -- \\
\hline
\end{tabular}

In all runs water/fiber weight ratio was $5 / 1$. Catalyst was aluminum sulfate. Amount of catalyst was based on original dry weight of straw. 


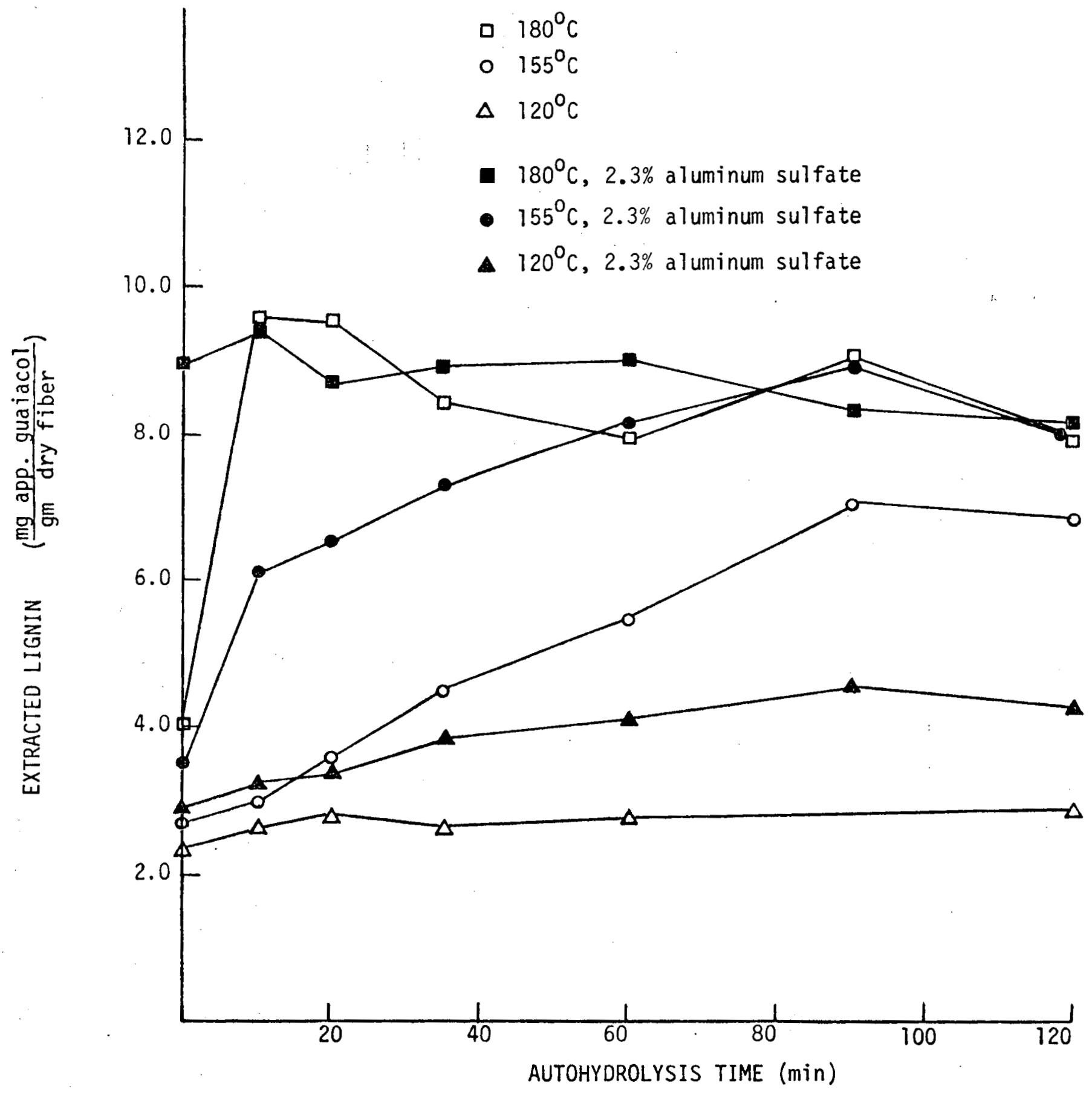

Figure 9. Effects of temperature and Lewis acid catalysis on the production of water soluble lignin during the autohydrolysis of wheat straw. In all cases the water/fiber weight ratio during autohydrolys is was $5 / 1$. Aluminum sulfate addition and lignin yield are based on the original dry weight of the straw. 
of the data in Figures 7 and 9 for the runs at $155^{\circ} \mathrm{C}$ indicates that the approach to maximum yield was much more rapid in the latter case. It appeared that the maximum amount of 1ignin that could be extracted was 8-10 mg apparent guaiacol per gm dry fiber. This level was reached after 0-10 min of autohydrolysis in the runs at $180^{\circ} \mathrm{C}$, but only after 60-90 min in the catalyzed run at $155^{\circ} \mathrm{C}$, and not even after $120 \mathrm{~min}$ in the other runs. Given that untreated wheat straw is expected to contain 5-15\% (w/w) 1ignin (16), a maximum depolymerization of 8-10 mg per gm seems low, especially in view of the high reactivity of treated material towards cellulase enzymes (see below). One explanation for this apparent anomaly is that calibration of the Pear1-Benson assay with guaiacol results in underestimation of the amount of dissolved lignin. Alternatively, it may be that only part of the depolymerized lignin is water soluble.

Figure 10 shows the yield of reducing sugar obtained from enzymatic hydrolysis of autohydrolyzed wheat straw as a function of the autohydrolysis conditions. In general, the pattern presented by this family of curves parallels that observed in Figure 9, underscoring the importance of lignin removal in enhancing the availability of cellulose to enzymatic attack. The greatest yield was obtained from material pretreated at $180^{\circ} \mathrm{C}$ in the presence of aluminum sulfate. However, it is important to note that the maximum yields from samples treated at $180^{\circ} \mathrm{C}$ without catalyst and at $155^{\circ} \mathrm{C}$ with catalyst were nearly equivalent. As shown in Figure 11, the fractional conversions of cellulose in these two cases were $50 \%$ and $45 \%$ respectively. Prior experience (9) suggests that in both cases conversion would exceed $80 \%$ if the enzymatic hydrolysis time were prolonged to $24-48 \mathrm{hr}$.

In the catalyzed run at $155^{\circ} \mathrm{C}$, a pretreatment time of about 60 min was required to obtain the maximum yield from enzymatic hydrolysis. Recalling the data in Figure 7, we see that the 60 min pretreatment also resulted in a maximum 


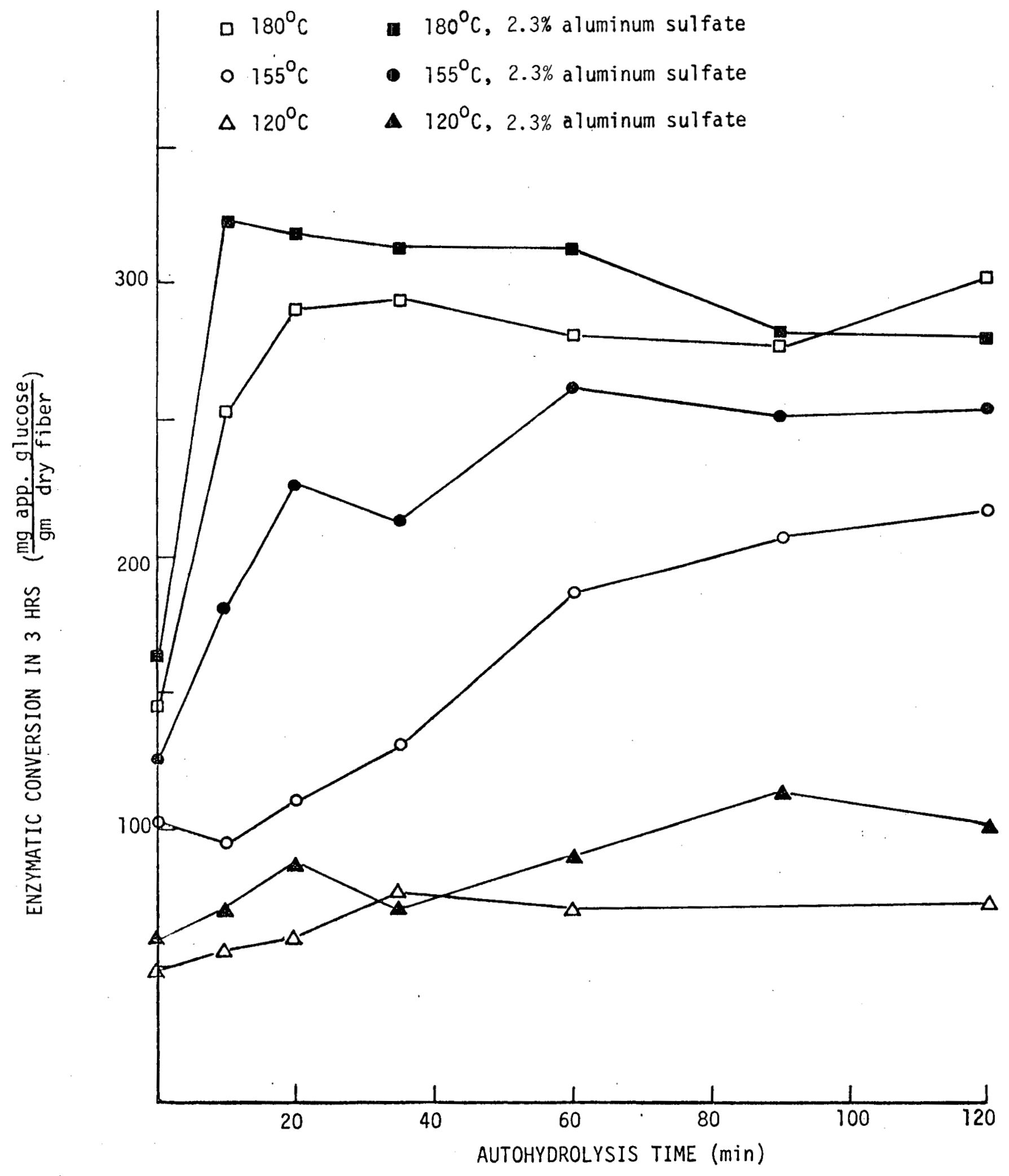

Figure 10. Effects of temperature and Lewis acid catalysis during autohydrolysis on the subsequent yield of reducing sugar in a standardized $3 \mathrm{hr}$ enzymatic hydrolys is of autohydrolyzed wheat straw. In all cases, the water/fiber weight ratio during autohydrolys is was $5 / 1$. Aluminum sulfate addition is based on the original dry weight of the straw. Sugar yield is based on the dry weight of the autohydrolyzed straw. 


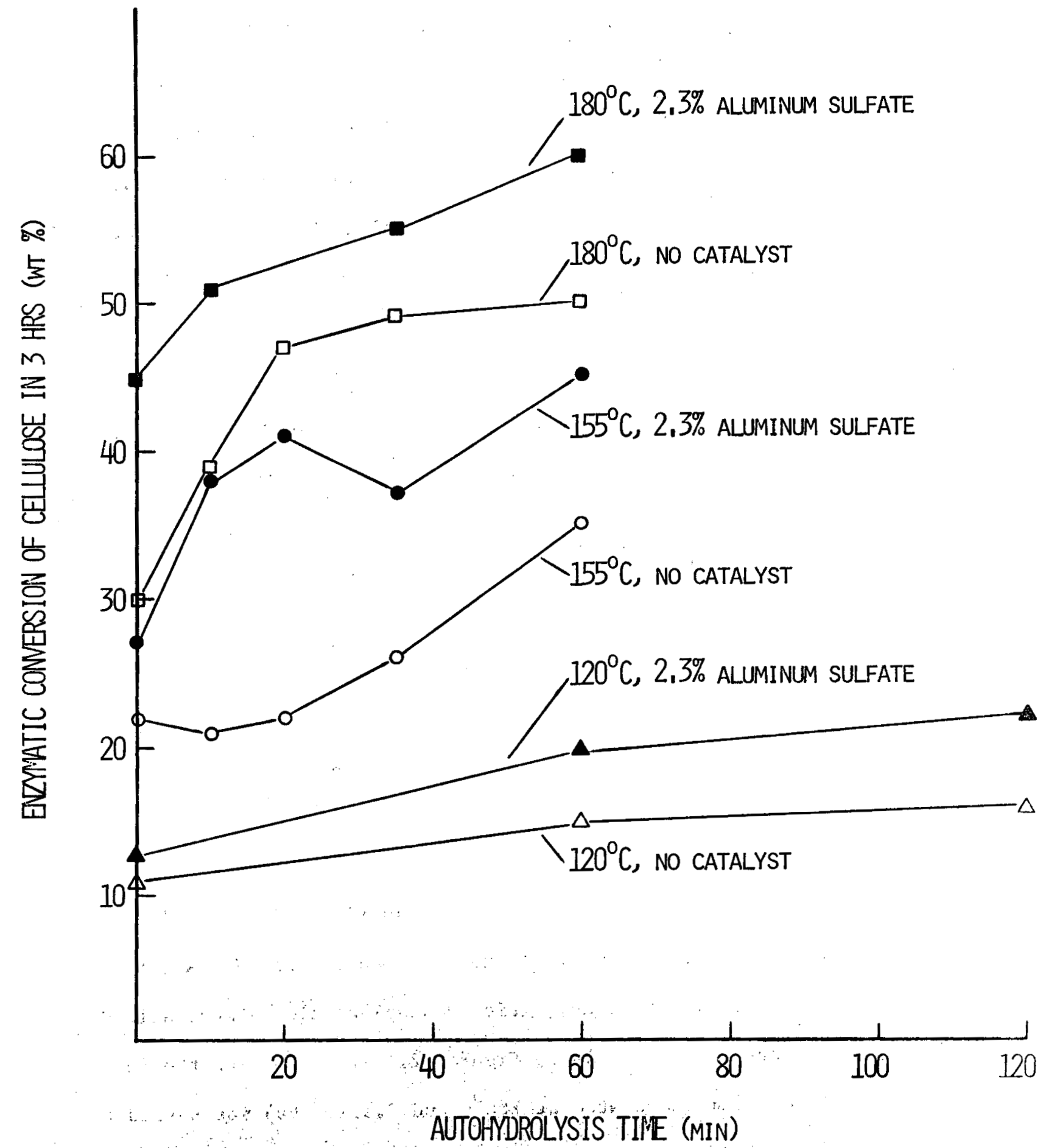

Figure 11. Fractional conversion of cel untose during standard 3 hr enzymatic hydrolysis of autohydrolyzed wheat straw as a function of auto$\therefore$ hydrolysis conditions. All autohydrolys is operations were carried out at a water/fiber weight ratio of $5 / 1$. Fractional conversion was computed as $0.9(S / C)$ where $S$ is the yield of reducing sugar as given in Figure 10 and $C$ is the cellulose percentage at the start of enzymatic hydrolys is as given in Table 7. The factor 0.9 accounts for the water molecule added during hydrolysis. 
yield of reducing sugar from autohydrolysis of hemicellulose. Consequently, it appears that a pretreatment process utilizing geothermal water at $155^{\circ} \mathrm{C}$ can result in nearly optimal conversion of wheat straw to fermentable sugars if the pretreatment is prolonged to $60 \mathrm{~min}$ and aluminum sulfate is added to the water. Of course, this increase in geothermal applicability is obtained at increased processing cost due to the longer residence time required and the consumption of catalyst.

\section{Enzyme Hydrolysis Studies}

The substrate concentration and enzyme/substrate ratio used in our standard $3 \mathrm{hr}$ enzymatic hydrolysis of autohydrolyzed straw were chosen to give a large degree of hydrolysis in a relatively short period of time. This was convenient in determining the effects of various autohydrolysis parameters on the hydrolyzability of the treated straw. However, these conditions would not be economically viable in a commercial process because they result in a dilute glucose syrup and require the use of large amounts of (expensive) enzyme. Consequently, we conducted a series of experiments designed to determine the effects of substrate concentration and enzyme/substrate ratio on both the yield of glucose and its concentration in the product solution.

For this study, $100 \mathrm{gm}$ of raw wheat straw was mixed with $250 \mathrm{~m} 1$ of distilled water containing $2.3 \mathrm{gm}$ of aluminum sulfate and then loaded into a 3.8-1iter autoclave (Autoclave Engineers, Inc., Erie, Pennsylvania). A schematic drawing of the treatment apparatus is shown in Figure 12. After bolting the reactor lid in place, live steam (generated at $260^{\circ} \mathrm{C}$ and $3.5 \times 10^{6} \mathrm{~Pa}$ ) was passed through the straw. This raised the temperature of the straw to the desired $180^{\circ} \mathrm{C}$ in about $30 \mathrm{sec}$. This temperature was then maintained within $\pm_{2}^{\circ} \mathrm{C}$ for 20 min by manually manipulating valves in the inlet and vent lines. At the end of this period, the reactor was completely vented and the treated straw rapidly removed. 

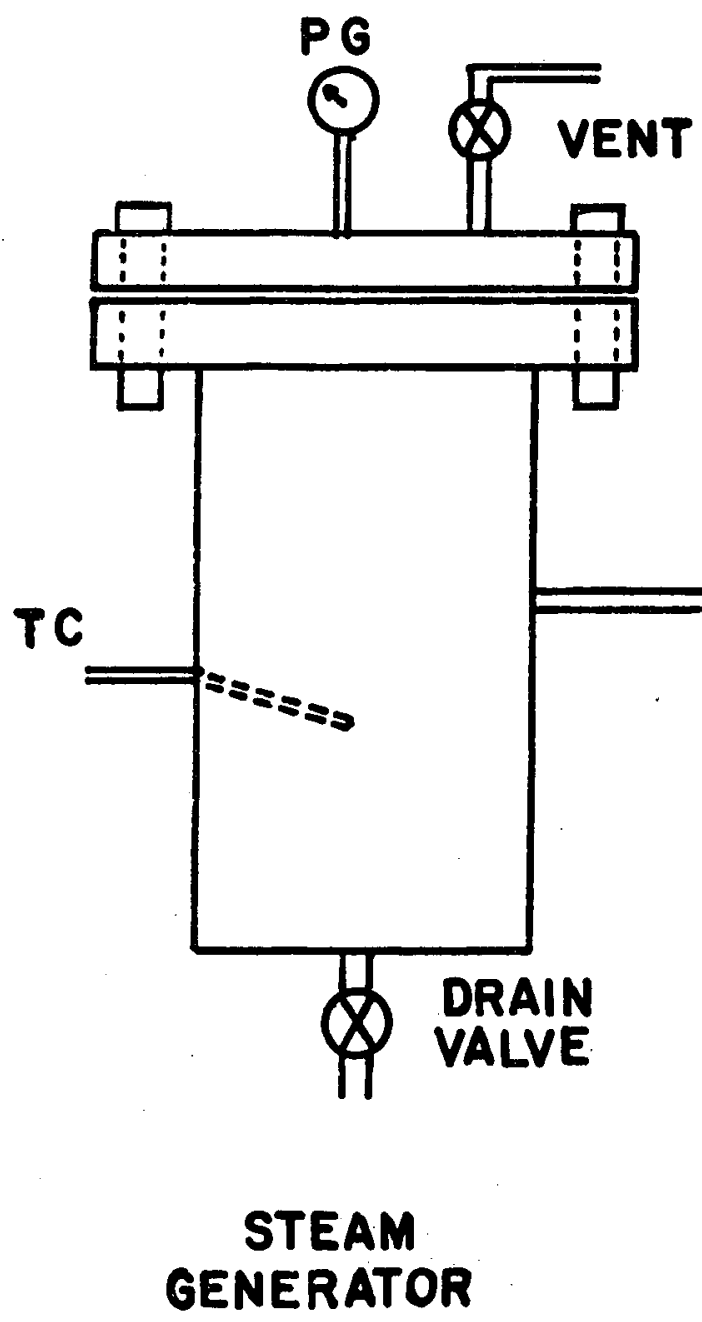

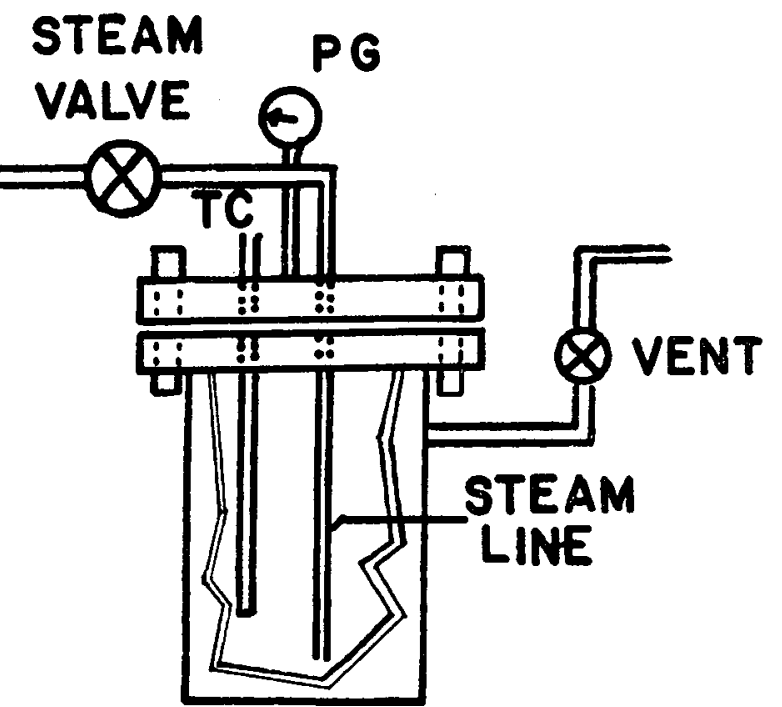

REACTION VESSEL

Figure 12. Schematic of large-scale autohydrolysis apparatus. $P G=$ Pressure Gauge; TC = Thermocouple well. 
Following this, the straw was subjected to two washings with $500 \mathrm{ml}$ aliquots of boiling distilled water and then allowed to air dry. Under the conditions described above, the catalyst/straw ratio during autohydrolysis was $2.3 \%$ (w/w). The water/straw weight ratio was initially 2.5/1; however, condensation of steam during the run raised this ratio to the $5 / 1$ value used in the small-scale procedure.

For enzyme hydrolysis, a stock solution was made up by combining $15 \mathrm{gm}$ cellulase (Novo SP 122) with $7.5 \mathrm{gm}$ cellobiase (Novo $250 \mathrm{~L}$ ) and diluting to $100 \mathrm{ml}$ with $0.1 \mathrm{M}$ citrate buffer at $\mathrm{pH} 4.8$. Portions of this solution were then diluted with additional buffer to achieve the enzyme levels shown in Table 8 . For each combination of solids concentration and enzyme/substrate ratio, twelve replicate samples were prepared and incubated at $50^{\circ} \mathrm{C}$. Two samples from each group were then withdrawn at $3,6,12.5,24,33.5$ and $48 \mathrm{hr}$ and analyzed for total reducing sugar with 3,5-dinitrosalicylic acid reagent and for glucose with glucose oxidase reagent.

As shown in Tables 9 and 10, the quantity of reducing sugar that was produced generally increased steadily, but at an ever decreasing rate, with time. In a few cases, however, it appeared that the amount actually decreased during the last time period. This may have been artifactual (analytical error) or the result of transglycosylation reactions. The latter explanation would be most likely to be correct in the case of Group 5 where the concentrations of sugar and enzyme were quite high; however, a similar decrease was not observed in Group 6 where these concentrations were even higher.

Initially, the yield of reducing sugar (see Table 9) increased monotonically with increasing enzyme/substrate ratio. At times greater than $6 \mathrm{hr}$, however, the yields from the reaction mixtures with ratios of $60 \mathrm{IU} / \mathrm{gm}$ and $80 \mathrm{IU} / \mathrm{gm}$ fell below that for the $40 \mathrm{IU} / \mathrm{gm}$ mixture. The most likely explanation 
Table 8. Initial compositions of reaction mixtures used in study of kinetiçs of enzymatic hydrolysis of autohydrolyzed wheat straw.

\begin{tabular}{ccc} 
Group & $\begin{array}{c}\text { Substrate Concentration } \\
(\text { wt } \%)\end{array}$ & $\begin{array}{c}\text { Enzyme/Substrate } \\
\text { Ratio } \\
(\text { IU/gm) }\end{array}$ \\
\hline 1 & 2.00 & 10.0 \\
2 & 3.33 & 16.7 \\
3 & 4.00 & 20.0 \\
4 & 8.00 & 40.0 \\
5 & 12.00 & 60.0 \\
6 & 16.00 & 80.0 \\
\hline
\end{tabular}

a Autohydrolysis conducted at $180^{\circ} \mathrm{C}$ for $20 \mathrm{~min}$ with water/straw weight ratio of $5 / 1$ and catalyst concentration of $2.3 \mathrm{gm}$ aluminum sulfate/ $100 \mathrm{gm}$ straw.

b Enzyme activity in International Units (IU) determined by filter paper assay of Mandels and Sternberg (J. Ferm. Technol., 54:267-286, 1976). 
Table 9. Yield of reducing sugar at various times during enzyme hydrolysis of autohydrolyzed wheat straw. a,b

\begin{tabular}{ccccccc}
\hline & \multicolumn{5}{c}{ Hydrolysis Time (hr) } \\
Group ${ }^{c}$ & 3.0 & 6.0 & 12.5 & 24.0 & 33.5 & 48.0 \\
\hline 1 & 114 & 167 & 250 & 325 & 358 & 388 \\
2 & 186 & 243 & 322 & 420 & 473 & 497 \\
3 & 197 & 258 & 384 & 457 & 472 & 446 \\
4 & 242 & 335 & 425 & 517 & 558 & 574 \\
5 & 244 & 343 & 411 & 472 & 506 & 446 \\
6 & 245 & 322 & 375 & 449 & 450 & 441 \\
\hline
\end{tabular}

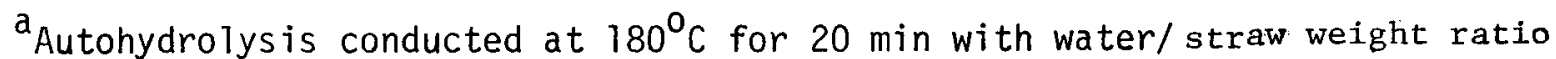
of $5 / 1$ and catalyst concentration of $2.3 \mathrm{gm}$ aluminum sulfate/100 gm straw.

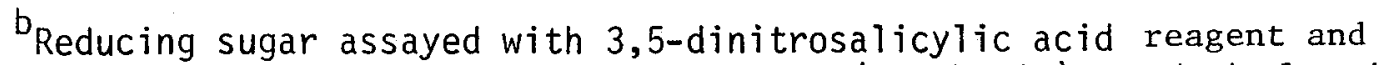
expressed as mg apparent glucose per gm (dry basis) autohydrolyzed straw.

${ }^{\mathrm{C}}$ See Table 8 for initial solids concentration and enzyme/substrate ratio. 
Table 10. Concentration of reducing sugar at various times during enzyme hydrolysis of autohydrolyzed wheat straw. $a, b$

\begin{tabular}{ccccccc}
\hline Group $^{c}$ & \multicolumn{5}{c}{ Hydrolysis Time (hr) } \\
\hline 1 & 3.0 & 6.0 & 12.5 & 24.0 & 33.5 & 48.0 \\
\hline 2 & 2.32 & 3.41 & 5.10 & 6.63 & 7.30 & 7.92 \\
3 & 6.41 & 8.38 & 11.1 & 14.5 & 16.3 & 17.1 \\
4 & 8.21 & 10.8 & 16.0 & 19.0 & 19.7 & 18.6 \\
5 & 21.0 & 29.1 & 37.0 & 45.0 & 48.5 & 49.9 \\
6 & 33.3 & 46.9 & 56.0 & 64.4 & 69.0 & 60.8 \\
\hline
\end{tabular}

autohydrolys is conducted at $180^{\circ} \mathrm{C}$ for $20 \mathrm{~min}$ with water/straw weight ratio of $5 / 1$ and catalyst concentration of $2.3 \mathrm{gm}$ aluminum sulfate $/ 100 \mathrm{gm}$ straw

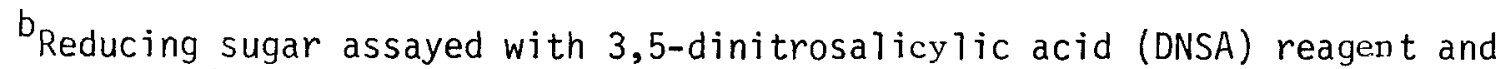
expressed as mg apparent glucose per ml.

${ }^{C_{S e e}}$ Table 8 for initial solids concentration and enzyme/substrate ratio. 
for this pattern is that the accumulation of glucose in the $60 \mathrm{IU} / \mathrm{gm}$ and $80 \mathrm{IU} / \mathrm{gm}$ mixtures was high enough to cause product inhibition of enzyme activity. Indeed, Table 10 shows that in these cases the reducing sugar concentration exceeded $50 \mathrm{mg} / \mathrm{ml}$ after reaction times of $6 \mathrm{hr}$.

The hydrolysis conditions represented by Group 4, initial solids concentration $=8 \%(\mathrm{w} / \mathrm{w})$ and enzyme/substrate ratio $=40 \mathrm{IU} / \mathrm{gm}$, appeared to strike

' the best compromise between conversion of cellulose to glucose and glucose concentration in the product solution. The yield of $570 \mathrm{mg}$ reducing sugar per gm autohydrolyzed straw, approximately $90 \%$ of which asayed as glucose, was the highest observed in this series of experiments. The final glucose concentration, about $45 \mathrm{mg} / \mathrm{m} 1$, although lower than the concentrations achieved with Group 5 and Group 6, was obtained with the use of less enzyme. Conventional wisdom (17) has it that profitable operation will limit enzyme usage to $10 \mathrm{IU} / \mathrm{gm}$. If the reaction mixture must contain $40 \mathrm{IU} / \mathrm{gm}$, this criterion can be met if $75 \%$ of the enzyme can be separated from the product solution and recycled. On the other hand, if the reaction mixture must contain $80 \mathrm{IU} / \mathrm{gm}$, then a less likely to be realized recycle ratio of $87.5 \%$ is required.

\section{Fermentation Study}

This work was designed to determine the ultimate yield of ethanol obtainable from wheat straw using the process shown in Figure 1. For this investigation, a total of $550 \mathrm{gm}$ (dry weight) of raw straw was autohydrolyzed in several runs conducted in the manner described in the previous section. Following autohydrolysis, the straw was washed twice with boiling distilled water using (each time) a water/straw weight ratio of $5 / 1$ based on the original dry weight of the straw. The washed material was then subjected to enzymatic hydrolysis. in a 7-1iter vessel (Micro Ferm Mode1 MF-114; New Brunswick Scientific Co., Edison, N. J.) equipped with a mechanical agitator. 
For the enzymatic hydrolysis procedure, $200 \mathrm{gm}$ (dry weight) of treated straw was combined with 1.58 liters of enzyme solution $(5.44 \mathrm{IU} / \mathrm{ml}), 90 \mathrm{ml}$ of oxytetracycline solution and 4.42 liters of 0.1 M citrate buffer. This mixture corresponds to an initial enzyme/substrate ratio of $43 \mathrm{IU} / \mathrm{gm}$ treated straw. The hydrolysis was allowed to proceed for $44 \mathrm{hr}$ at $50^{\circ} \mathrm{C}$ and $\mathrm{pH} 4.6$ with continuous agitation of $300 \mathrm{rpm}$. Periodically samples were withdrawn and analyzed for reducing sugar by reaction with 3,5-dinitrosalicylic acid reagent. As shown in Figure 13, although the hydrolysis was carried out for $44 \mathrm{hr}$, very little additional sugar was produced after $20 \mathrm{hr}$. Hence, the maximum conversion of cellulose resulted in a liquor with a reducing sugar concentration of 16.8 $\mathrm{nng} / \mathrm{ml}$. This value, as we11 as all data shown in Figure 13, have been corrected (downward) to account for the reducing sugar present in the form of lactose in the enzyme preparation.

In order to determine the percent cellulose conversion achieved during enzyme hydrolysis, fiber assays were performed on the raw wheat straw and on samples taken after autohydrolysis and enzyme digestion. Results of these analyses are shown in Table 11. Based on the cellulose percentage in the autohydrolyzed straw and the production of reducing sugar during enzyme hydrolysis, it can be calculated that the conversion efficiency was approximately $78 \%$. Comparison of the cellulose percentages in the samples taken before and after enzyme hydrolysis would indicate a somewhat higher level of conversion. However, the results obtained for the enzyme-hydrolyzed sample are questionable, since this material was extremely difficult to handle in the fiber analysis procedures. It may be noted in passing that the level of hemicellulose in the autohydrolyzed sample was very low indicating nearly complete conversion of this fraction in the pretreatment step. 


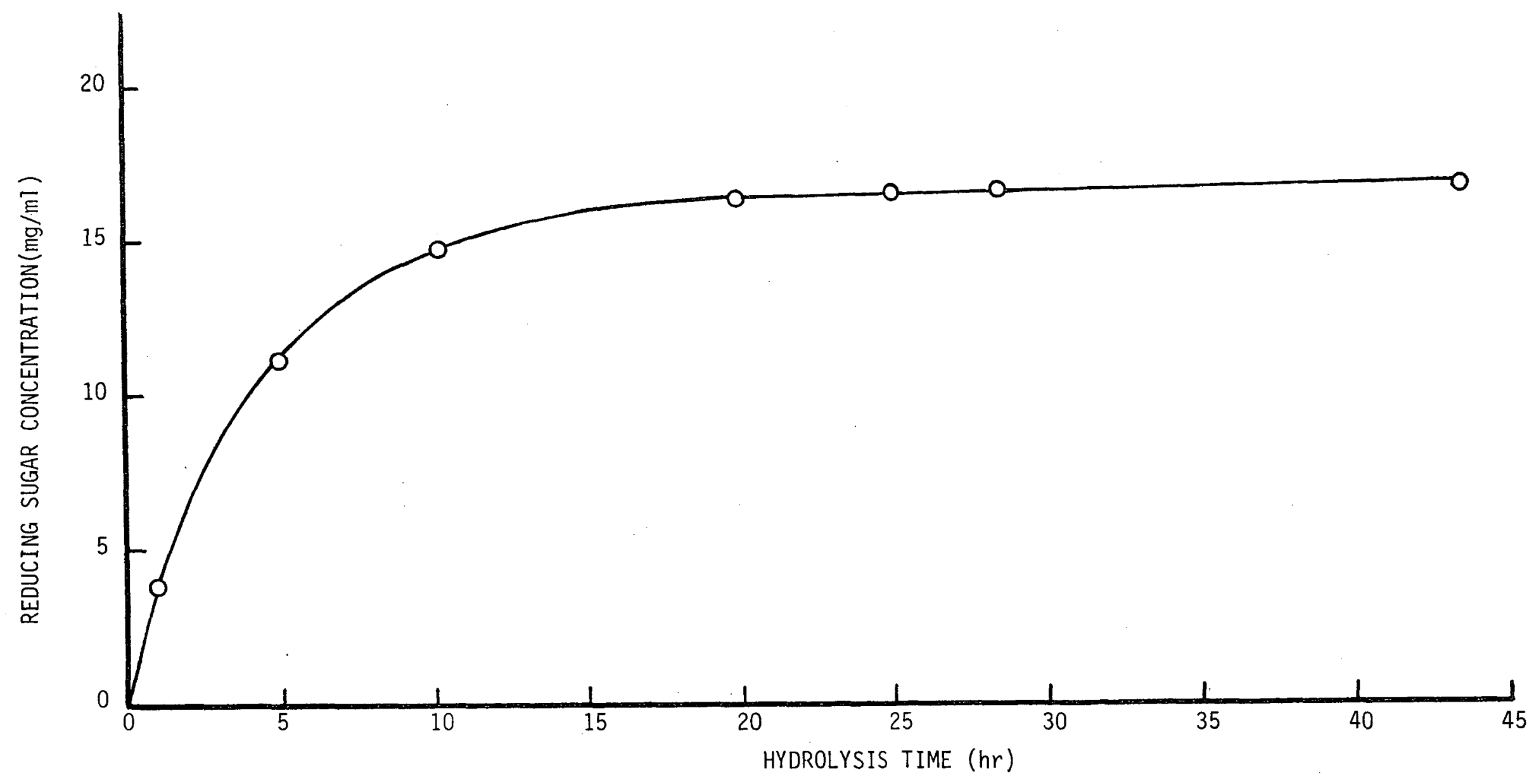

Figure 13. Reducing sugar concentration vs time for large-scale enzymatic hydrolysis of autohydrolyzed wheat straw. Autohydrolys is was carried out at $180^{\circ} \mathrm{C}$ for $20 \mathrm{~min}$ with a water/straw weight ratio of $5 / 1$ and $2.3 \%$ (based on dry weight of straw) aluminum sulfate added. Initial substrate concentration and enzyme/substrate ratio were $33 \mathrm{gm} / 1$ iter and $43 \mathrm{IU} / \mathrm{gm}$. Reducing sugar was determined by reaction with 3,5-dinitrosalicylic acid reagent. Values are given as glucose equivalents and are corrected for lactose present in enzyme preparation. 
Table 11. Fiber analysis data for wheat straw samples at different processing stages.

\begin{tabular}{lcccc}
\hline Sample & $\begin{array}{c}\text { Hemicellulose } \\
(\%)\end{array}$ & $\begin{array}{c}\text { Cellulose } \\
(\%)\end{array}$ & $\begin{array}{c}\text { Lignin } \\
(\%)\end{array}$ & $\begin{array}{r}\text { Ash } \\
(\%)\end{array}$ \\
\hline Untreated $^{\mathrm{b}}$ & 23.8 & 35.8 & 6.0 & 0.61 \\
$\begin{array}{l}\text { Autohydrolyzed } \\
\text { c }\end{array}$ & 2.8 & 58.6 & 10.7 & 3.9 \\
$\begin{array}{l}\text { Autohydrolyzed and } \\
\text { Enzyme Digested }\end{array}$ & 2.7 & 12.1 & 10.5 & 5.2 \\
\hline
\end{tabular}

apercentages based on dry weight.

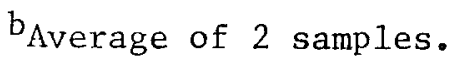

cAverage of 3 samples.

$\mathrm{d}_{1}$ sample only taken after $44 \mathrm{hr}$ of enzyme hydrolysis. 
After being filtered to remove undigested fiber particles, the liquor from the enzyme hydrolysis operation was utilized in an ethanol fermentation with conventional baker's yeast. Fermentation was carried out in the same 7-liter vessel as used for the enzyme hydrolysis. To inftiate fermentation, 3.6 liters of filtered liquor was fortified with trace nutrients (to give a medium with the composition shown in Table 12) and then inoculated with $400 \mathrm{ml}$ of pre-adapted yeast culture. Conditions were maintained as follows:

$$
\begin{aligned}
\text { temperature } & =30^{\circ} \mathrm{C} \\
\mathrm{pH} & =4.8 \\
\text { agitation rate } & =300 \mathrm{rpm} \\
\text { aeration rate } & =0.1 \text { iiter } / \text { iter } / \mathrm{min}
\end{aligned}
$$

As shown in Figure 14, the ethanol concentration peaked at $5.8 \mathrm{gm} /$ liter about $12 \mathrm{hr}$ after inoculation. The subsequent decrease in ethanol concentration was caused by dilution of the fermentor contents through the addition of acid and base for $\mathrm{pH}$ control. The ratio of ethanol produced to sugar consumed was $0.46 \mathrm{gm} / \mathrm{gm}$, which is $90 \%$ of the theoretical value of $0.51 \mathrm{gm} / \mathrm{gm}$. This lower than theoretical yield was attributed to sugar consumption for buildup of cell mass and to the use of non-optimized fermentation conditions. The residual sugar present in the final fermentation broth was probably non-fermentable carbohydrate carried through the process. This would include lactose from the enzyme preparation and pentoses from the enzymatic hydrolysis of residual hemlectlujose.

In summary, this large scale experiment was quite successful. It confirmed all results obtained during earlier bench-scale experimentation. A high level of cellulose conversion was achieved during enzymatic hydrolysis, and the sugars thus produced were almost completely utilized during a subsequent yeast fermentation. Even the ethanol yield from the latter can be considered quite good, considering that no attempt was made to optimize fermentation conditions. 
Table 12. Medium composition for baker's yeast fermentation.

\begin{tabular}{cc}
\hline Component & $\begin{array}{c}\text { Concentration } \\
\text { (gm/liter) }\end{array}$ \\
\hline Reducing sugar ${ }^{\mathrm{b}}$ & 18.1 \\
$\mathrm{Na}_{2} \mathrm{HPO}_{4} \cdot 7 \mathrm{H}_{2} \mathrm{O}$ & 3.9 \\
$\mathrm{KH}_{2} \mathrm{PO}_{4}$ & 0.5 \\
$\mathrm{MgSO}_{4}$ & 0.5 \\
$\mathrm{CaCl}_{2}$ & 0.28 \\
$\mathrm{Citric}_{2}$ acid & 4.3 \\
$\mathrm{Na}^{2} \mathrm{citrate}$ & 1.25 \\
$\mathrm{NH}_{4} \mathrm{Cl}$ & 8.0 \\
$\mathrm{Yeast}$ extract & 8.0 \\
\hline
\end{tabular}

${ }^{a}$ Prepared by adding nutrients to filtered enzymatic hydrolyzate.

${ }^{b}$ Determined by reaction with 3,5-dinitrosalicylic acid reagent and expressed as glucose equivalent without applying any corrections for presence of lactose or other non-glucose sugars. 


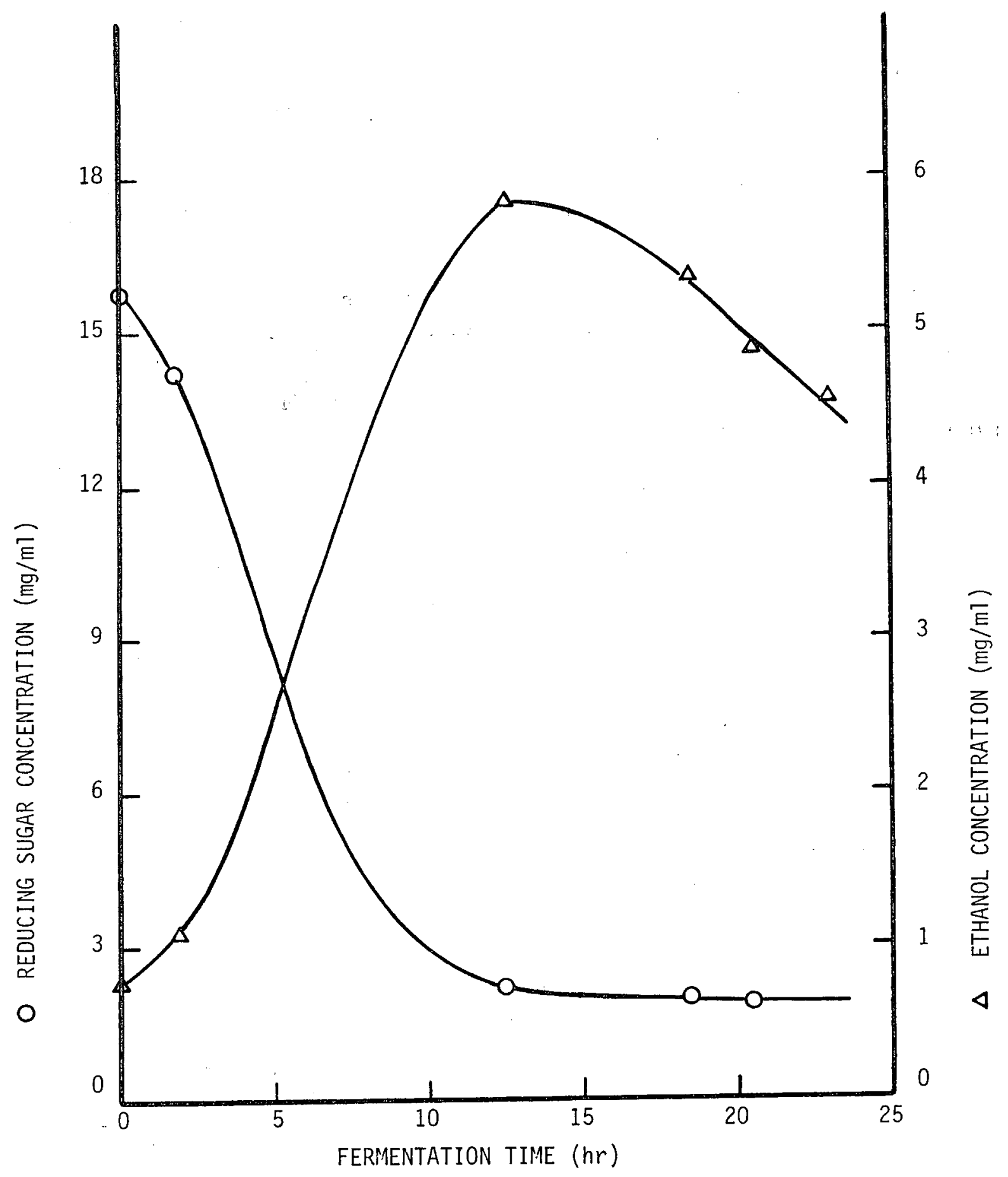

Figure 14. Kinetics of baker's yeast fermentation of sugars obtained from large-scale enzymatic hydrolys is of autohydrolyzed wheat straw. Ethanol was determined by gas chromatography, and reducing sugar by reaction with 3,5-dinitrosalicylic acid reagent. Reducing sugar values are expressed as glucose equivalents. 
Based on these results, one could conservatively estimate a yield of 45 gal of ethanol per ton of wheat straw containing $40 \%(w / w)$ cellulose. Effects of Direct Use of Geotherma1 Water

In this series of experiments, we investigated the effects of direct use of geothermal water in each of the major processing, steps shown in Figure 1 . Such direct usage is highly desirable, since it lowers costs (by eliminating the need to purify process water) and increases thermal efficiency (by eliminating the need to heat exchange process water against the geotherma1 source). For a description of the source and composition of the geothermal water used in this study, see appropriate section of MATERIALS AND METHODS.

Autohydrolysis. Figures 15 and 16 depict results obtained when geothermal water was used in place of distilled water in constituting water/straw mixtures with a weight ratio of 5/1. At this stage in our work, we were also considering the addition of phenol to the autohydrolysis charge to promote delignification (8). Since interactions between contaminants in the geothermal water and phenol were thought possible, the latter was added to each charge in the ratio 0.2 parts phenol per 100 parts wheat straw. As shown in Figure 15, the use of geotherma1 water resulted in the same peak value for extracted sugar as was obtained in the comparable run with distilled water. However, the decline from the peak value with increasing autohydrolysis time was less precipitous than that observed in the latter run. Figure 16 shows that enzymatic hydrolysis of the materials autohydrolyzed with geothermal water resulted in somewhat lower (though probably not significantly: lower) yields of reducing sugar than were obtained when distilled water was used in the autohydrolysis. Qualitatively, however, the shapes of the curves depicting enzymatic conversion vs autohydrolysis treatment time for these two runs were identical. On balance, these 


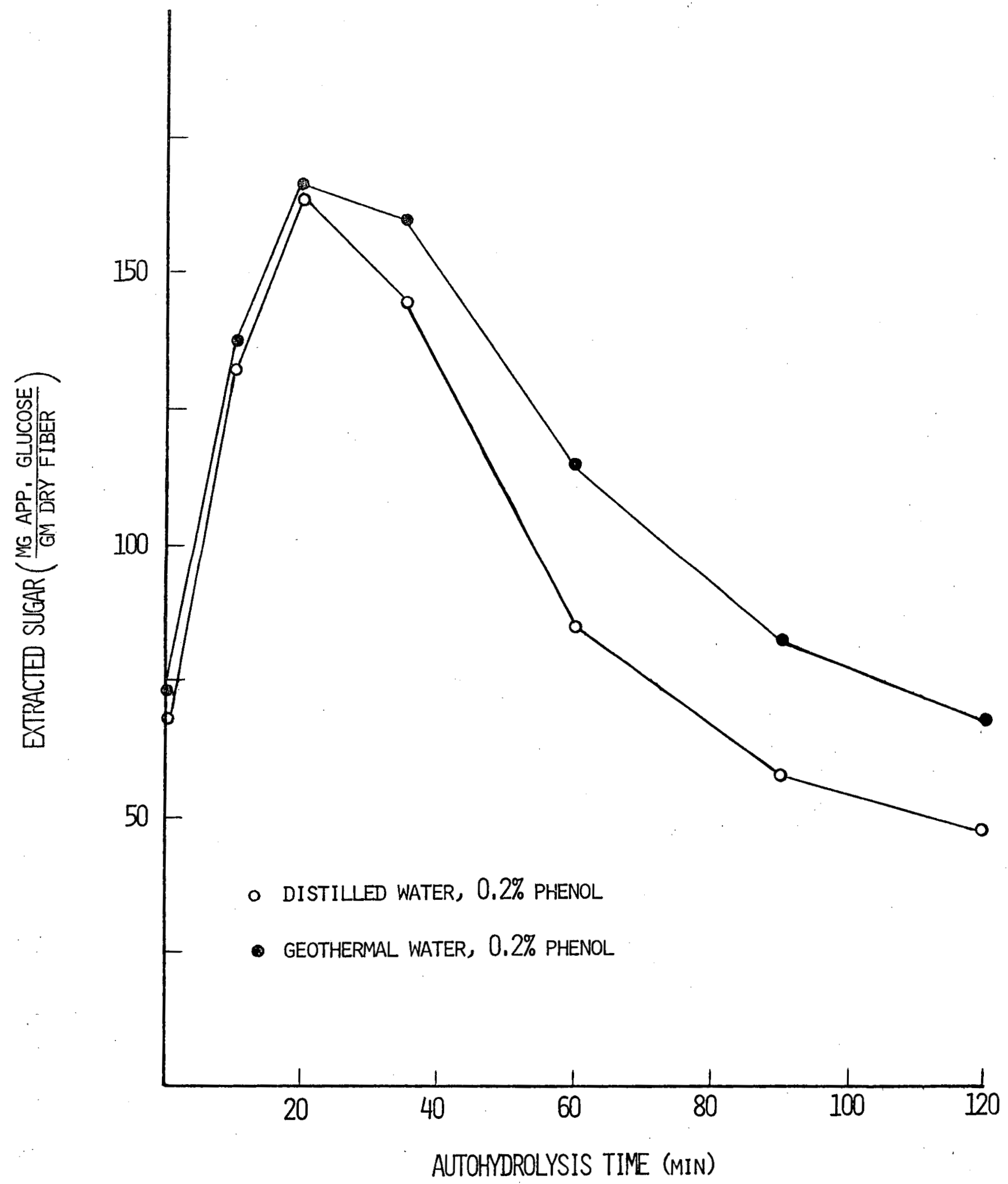

Figure 15. Effect of direct use of geothermal water on the yield of reducing sugar during the autohydrolys is of wheat straw at $180^{\circ} \mathrm{C}$. The water/straw weight ratio during autohydrolys is was $5 / 1$. Sugar yield and phenol addition are based on the original dry weight of the straw. 


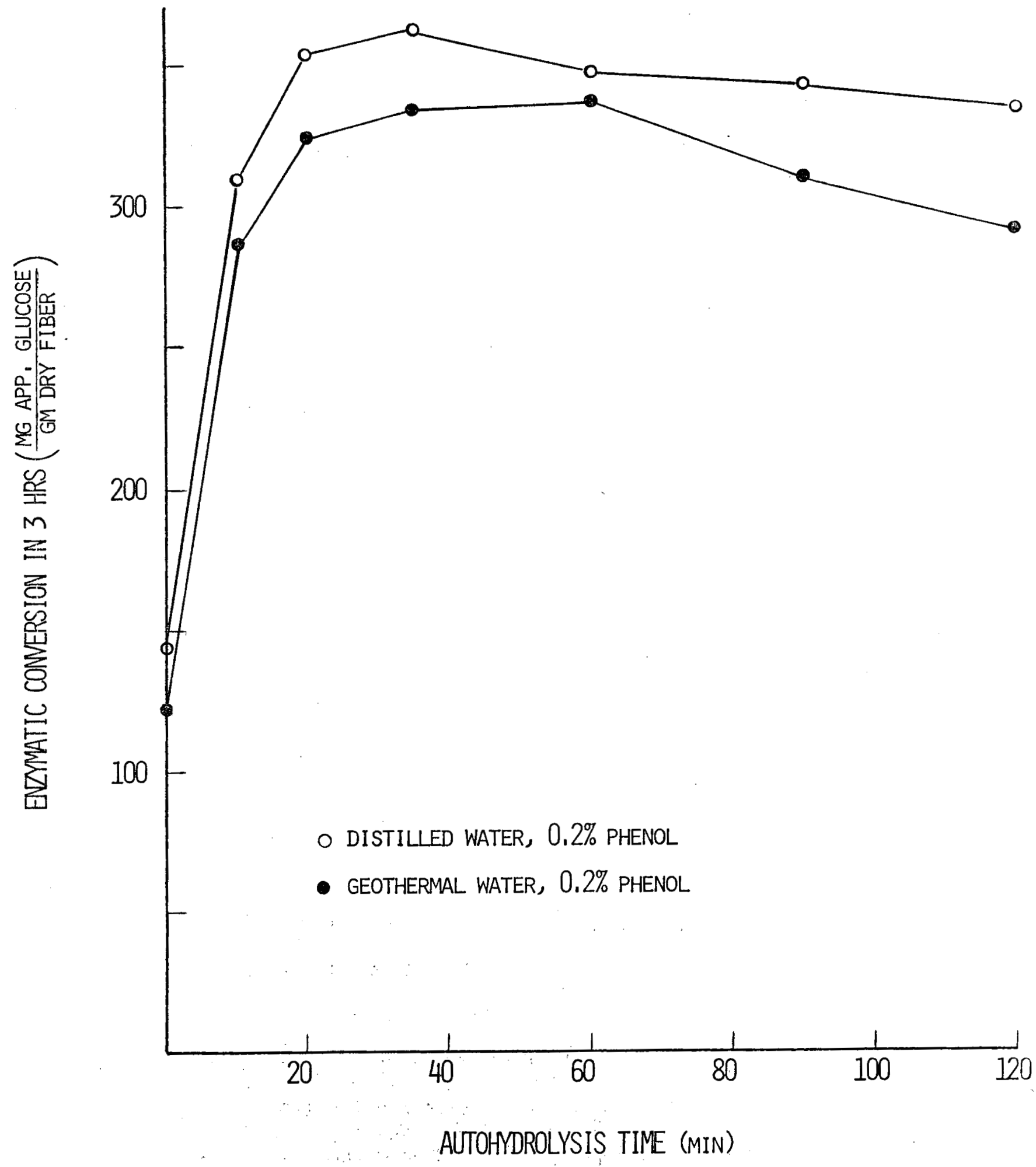

Figure 16. Effect of direct use of geothermal water in autohydrolys is of wheat straw at $180^{\circ} \mathrm{C}$ on the subsequent yield of reducing sugar during a standardized $3 \mathrm{hr}$ enzymatic hydrolysis. The water/ straw weight ratio during autohydrolys is was $5 / 1$. Phenol addition is based on the original dry weight of the straw. Sugar yield is based on dry weight of autohydrolyzed straw. 
results indicate that geothermal water can be used directly in the autohydro1ysis operation without compromising the yield of fermentable sugars.

Postautohydrolysis Extraction. Figure 17 presents evidence that the use of geothermal water in the postautohydrolysis extraction procedure has no effect on subsequent enzymatic hydrolysis. In this study, extraction of autohydrolyzed wheat straw with geothermal water, followed by two on-filter washes with either distilled water or geothermal water, resulted in the same yield of soluble reducing sugar. ( $330 \mathrm{mg}$ per gm dry fiber) in the standard $3 \mathrm{hr}$ enzymatic hydrolysis as did extraction and washing with distilled water. Enzymatic Hydrolysis. Potential inhibition of enzymatic hydrolysis by geothermal water was tested through the standard filter paper assay for cellulolytic enzyme activity (18). In this assay $50 \mathrm{mg}$ of filter paper (Whatman No. 1; Fisher Scientific Co., St. Louis, Missouri) is mixed with $3.0 \mathrm{ml}$ of enzyme solution and then incubated at $50^{\circ} \mathrm{C}$ for $30 \mathrm{~min}$. At the end of this period, the solution is analyzed for soluble reducing sugar by reaction with 3,5-dinitrosalicylic acid. The amount of reducing sugar produced is indicative of the level of enzyme activity.

For the purpose at hand, the enzyme solution was composed of $2.0 \mathrm{ml}$ of the stock enzyme solution used in our standard $3 \mathrm{hr}$ hydrolysis procedure (see MATERIALS AND METHODS) and $1.0 \mathrm{ml}$ of $0.1 \mathrm{M}$ citrate buffer at $\mathrm{pH} \mathrm{4.8.} \mathrm{In} \mathrm{control}$ runs the additional buffer was constituted with distilled water, and in test runs yielded $3.10 \pm 0.10 \mathrm{mg}$ reducing sugar per ml solution as compared to 2.96 $\pm 0.13 \mathrm{mg} / \mathrm{ml}$ for the control runs. Thus, replacement of $1 / 3$ of the liquid content of the assay mixture with geothermal water had no effect on enzyme activity.

Fermentation. Geothermal water also caused no inhibition of yeast fermentation as shown by the data in Table 13 . Four solutions containing $5 \%(\mathrm{w} / \mathrm{v})$ dextrose were fermented. Two were prepared with distilled water and two with 


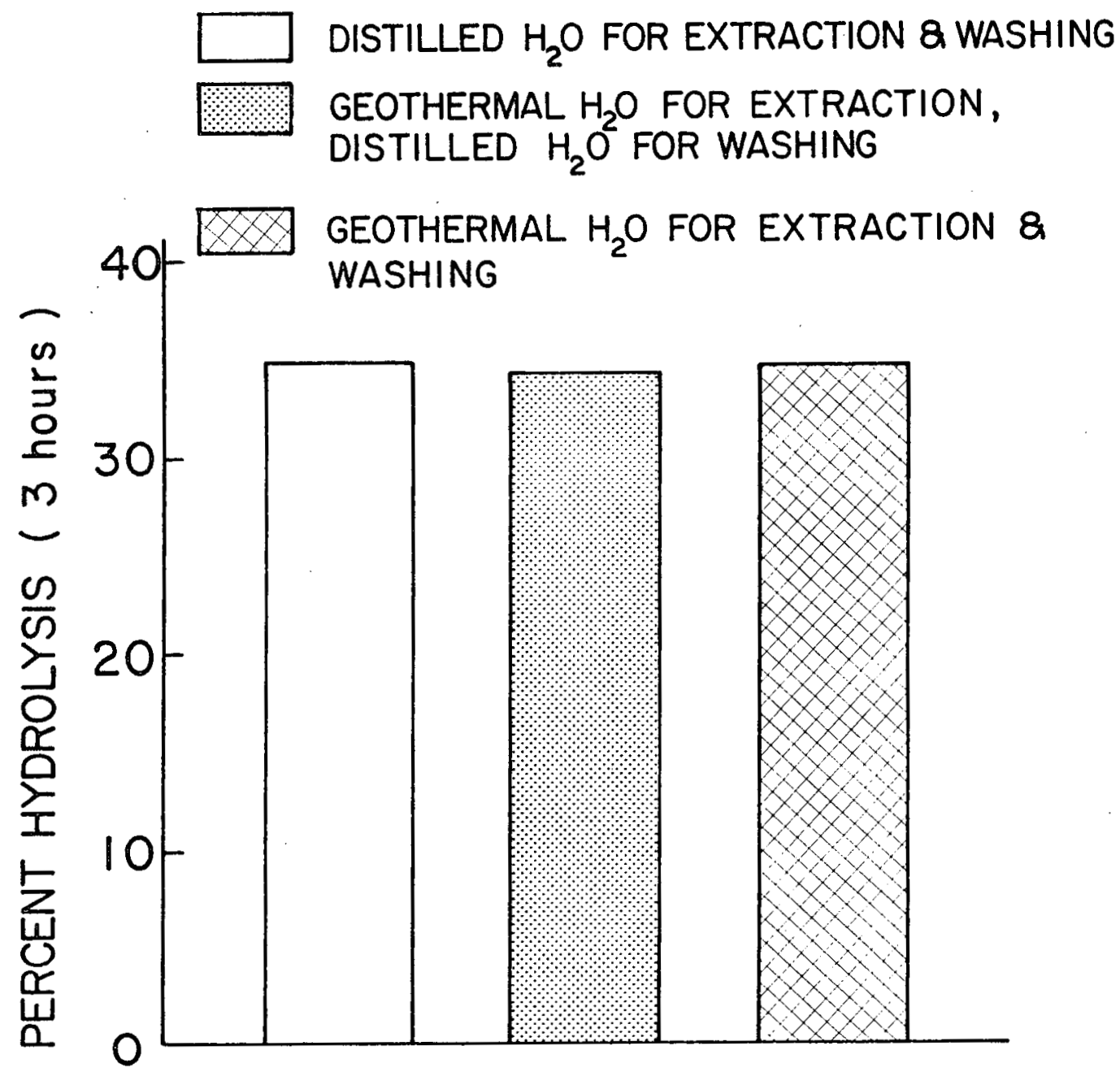

Figure 17. Effect of direct use of geothermal water in extraction and washing procedures on the subsequent yield of reducing sugar during a standardized $3 \mathrm{hr}$ enzymatic hydrolys is of autohydrolyzed wheat straw. The material used in these tests was autohydrolyzed at $180^{\circ} \mathrm{C}$ for $45 \mathrm{~min}$. The water $/ \mathrm{straw}$ weight ratio was $1 / 1$ at the start of the treatment, but it rose to 4/1 during the run as a result of steam condensation. A11 extractions were at ambient temperature for 10 min using a water/straw weight ratio of 10/1. Extraction was followed by two on-filter washes, also at ambient temperature, using a water/straw weight ratio of $5 / 1$. Weight ratios for extraction and washing are based on the actual dry weight of the autohydrolyzed straw. 
Table 13. Effect of geothermal water $\left(\mathrm{GTH}_{2} \mathrm{O}\right)$ on the fermentation of dextrose with baker's yeast?

\begin{tabular}{lc} 
Solution Composition & Apparent Degree of Fermentation ${ }^{\mathrm{b}}$ \\
$\begin{array}{l}350 \mathrm{~m} 1 \mathrm{GTH} \\
\quad+1.2 \mathrm{gm} \text { yeast extract }\end{array}$ & $101 \%$ \\
$350 \mathrm{ml} \mathrm{GTH} 20+17.5 \mathrm{gm}$ dextrose & $98 \%$ \\
$350 \mathrm{~m} 1 \mathrm{distilled} \mathrm{H}_{2} \mathrm{O}+17.5 \mathrm{gm}$ dextrose & $108 \%$ \\
+1.2 gm yeast extract & $102 \%$ \\
$350 \mathrm{ml}$ distilled $\mathrm{H}_{2} \mathrm{O}+17.5 \mathrm{gm}$ dextrose & \\
\hline
\end{tabular}

${ }^{\mathrm{a}}$ In a11 cases, inoculum was $35 \mathrm{gm}$ of baker's yeast cake.

$b_{\text {Computed as }} 100\left(\frac{G_{i}-G_{f}}{G_{f}}\right)$ where $G_{i}$ and $G_{f}$ are the initial and final values for the specific gravity of the solution determined by means of an hydrometer. 
geothermal water. Yeast extract was also added, to one solution in each group to insure that results would not be biased by an incomplete supply of yeast nutrients. Each solution was inoculated with $35 \mathrm{gm}$ of baker's yeast cake and placed in a rotary incubator (operating at $150 \mathrm{rpm}$ and ambient temperature) for 4 hours. Specific gravities were measured with an hydrometer at the beginning and end of this period to determine the apparent degree of fermentation. In all four cases, complete conversion of the dextrose was indicated.

\section{SUMMARY}

A detailed study has been made of the application of the geothermally assisted process shown in Figure 1 to the production of ethanol from wheat straw. The major findings in this work are given below.

1) The water/straw weight ratio during autohydrolysis should be greater than $2 / 1$ in order to insure complete wetting of the straw. This appears to be a requirement for obtaining a maximum degree of hemicellulose depolymerization. During most of this study, a ratio of $5 / 1$ was used with good results. Higher ratios may be used, but they do not appear to result in any improvement in the yield of fermentable sugars from either the autohydrolysis operation itself or the subsequent enzymatic hydrolysis of the residual solids. Consequently, the use of higher ratios is not attractive, since it leads to increased pumping costs and lowers the concentration in which the hemicellulosic sugars are recovered.

2) In uncatalyzed autohydrolysis runs, the maximum yield of reducing sugar from the autohydrolysis itself was about $270 \mathrm{mg}$ apparent glucose per gm straw after $10-20 \mathrm{~min}$ at $180^{\circ} \mathrm{C}$. At longer times, this yield decreased sharply due to degradation of the sugars to 5-hydroxymethylfurfural, 2-furfuraldehyde and other (unidentified) products. For solids recovered from the autohydrolysis after treatment times of 20 min or more, the conversion of cellulose to 
reducing sugar was about $50 \%$ in a standardized $3 \mathrm{hr}$ enzymatic hydrolysis. This projects to a conversion of $80-90 \%$ at longer (24-48 hr) hydrolysis times.

3) The addition of Lewis acid catalysts (such as aluminum sulfate) to the autohydrolysis charge appeared to promote hydrolysis of hemicellulosic polysaccharides, but not the degradation of the resulting sugars. Thus, yields of reducing sugar comparable to that cited above $(270 \mathrm{mg} / \mathrm{gm})$ were obtained after $20 \mathrm{~min}$ at $155^{\circ} \mathrm{C}$. To obtain maximum enzymatic conversion of the residual solids, however, it appeared that a treatment time of 60 min or more was required. The important implication here is, that geothermal wells producing water at $150-160^{\circ} \mathrm{C}$ can be successfully interfaced with the process by adding aluminum sulfate to the wheat straw feed and prolonging the treatment time to $60 \mathrm{~min}$.

4) The sugars formed during autohydrolysis seemed to derive from two sources, fructosans which are nonstructural polymers of fructose and glucose and structural hemicelluloses composed mainly of arabinose and xylose. The fructosans were readily saccharified even at $120^{\circ} \mathrm{C}$; whereas, the hemicelluloses evidenced no significant depolymerization below $155^{\circ} \mathrm{C}$. It appeared that even at $180^{\circ} \mathrm{C}$, much of the solubilized hemicellulose remained in oligomeric form. Since the fructosans, which may comprise $10-14 \%$ of the dry weight of the straw, are so readily hydrolyzed, it may be beneficial to employ a two-stage pretreatment. The sugars resulting from hydrolysis of fructosans could then be separated after the initial (low temperature) stage, thereby eliminating thermal degradation in the second (high temperature) stage designed for hydrolysis of the hemicelluloses.

5) Due, we think, to the low level of lignin in the wheat straw used in this study, it was not necessary to employ aqueous ethanol solutions or high temperatures in the postautohydrolysis extraction. Simple aqueous extraction at ambient temperature was sufficient to remove the solubilized carbohydrates, 
and no further improvement in the enzymatic conversion of residual solids was observed when aqueous ethanol and/or high temperature were employed in the extraction step. This represents a significant economic improvement over the process shown in Figure 1, since it eliminates the need to recover large amounts of solvent through distillation.

6) As expected, the enzymatic conversion of autohydrolyzed straw to glucose was significantly affected by both the substrate concentration and the enzyme/ substrate ratio. Of the combinations tested, the one with an initial substrate concentration of $8 \%(\mathrm{w} / \mathrm{w})$ and an enzyme/substrate ratio of $40 \mathrm{IU} / \mathrm{gm}$ seemed to offer the best compromise between conversion of cellulose to glucose and the glucose concentration in the product solution. In this instance, about $90-95 \%$ of the residual cellulose was converted to reducing sugar in the course of $48 \mathrm{hr}$. At least $90 \%$ of the reducing sugar assayed as glucose, giving a glucose concentration in the product solution of $4.5 \%(\mathrm{w} / \mathrm{w})$. Given present thinking on the economics of enzyme usage, it appears that a recovery system recycling $75 \%$ of the enzyme may be necessary.

7) In a 7-1iter fermentation of the sugar solution obtained from enzymatic hydrolysis of autohydrolyzed wheat straw, the conversion of glucose to ethanol was $90 \%$ of the theoretical value. Since no attempt was made to optimize fermentation conditions, even higher conversions may be possible. Based on this result and those discussed under item 6 , one can conservatively project an ethanol yield of 45 gal per ton of wheat straw containing $40 \%(w / w)$ cellulose.

8) It appeared that geothermal water of the quality produced at the Raft River Site (Malta, Idaho) could be used in all major process steps without compromising the yield of fermentable sugars or their subsequent fermentation to ethano1. This was actually not expected, and it may be that water of poorer quality cannot be used in the enzymatic hydrolysis or yeast fermentation steps. 
However, even if the latter concern is borne out, the ability to use geothermal water directly in the autohydrolysis and extraction steps is the major advantage, since it is in these operations that the greatest use of energy occurs.

\section{RECOMMENDATIONS FOR FUTURE WORK}

During the course of this work, several questions deserving of additional investigation became apparent:

1) Very good yields of fermentable sugars were obtained from both the autohydrolysis itself and the subsequent enzymatic hydrolysis of residual solids. Since this may have been due in part to the low level of lignin in the straw that was used, it would be valuable to know if the process conditions determined to be optimal in the current work are also applicable to straw derived from other varieties of wheat and from other cereal grains.

2) The ease with which fructosans can be extracted and hydrolyzed has not previously been appreciated. Since these sugars (glucose and fructose) are fermentable by yeast and can represent up to $10-14 \%(w / w)$ of the straw, it seems worthwhile to investigate a two-step pretreatment in which these sugars are recovered after the first (low temperature) step.

3) The sugars derived from autohydrolysis (with or without the glucose and fructose from decomposition of fructosans) must be fermented to realize an economic advantage from their isolation. Since there is virtually no information available on the fermentation of these mixed sugars, this is an area in need of much additional study.

4) It was noted above that the use of enzyme in the process must probably be limited to about $10 \mathrm{IU} / \mathrm{gm}$ straw for profitable operation. Since much higher enzyme/substrate ratios appear necessary to obtain high conversions and concentrated product solutions, the need for development of enzyme recovery and recycle systems is apparent. 


\section{ACKNOWLEDGMENTS}

The authors would like to express their appreciation to Krystal Dockrey, Bob Lewis, Lauri Binder and J. Y. Lee for their technical assistance on this project. Thanks are also due to Dick Schmitt and Jim Jacoby of EG\&G Idaho, Inc. for their advice and support. 


\section{REFERENCES}

1. Solomons, G.L. 1976. Solvents from carbohydrates: some economic considerations. Process Biochemistry, 11(3):32-37.

2. Moore, C.A. 1977. Is agriculture a viable renewable raw materials resource? Chemtech, $1: 762-765$.

3. Lora, J.H. and M. Wayman. 1978. Delignification of hardwoods by autohydrolysis and extraction. Tappi, 61(6):47-50.

4. Kleinert, T.N. 1974. Organosolv pulping with aqueous alcohol. Tappi, 57 $(8): 99-102$.

5. Polein, J. and B. Bezuch. 1977. Investigation on enzymic hydrolysis of lignified cellulosic materials. Wood Sci. Techno1., 11:275-290.

6. Wayman, M., J.H. Lora and E. Gulbinas. 1979. Material and energy balances in the production of ethanol from wood. pp 183-201 in M. Tomlinson (ed.) ACS Symposium Series No. 90. Chemistry for Energy. American Chemical Society: Washington, D.C.

7. Humphrey, A.E. 1977. Fermentation technology. Chem. Eng. Prog., 73(5): 85-91.

8. Wayman, M. and J.H. Lora. 1978. Aspen autohydrolysis. The effects of 2-naphtho1 and other aromatic compounds. Tappi, 61 (6):55-57.

9. Murphy, V.G., J.C. Linden and A.R. Moreira. 1980. Optimization of solvent extraction procedure for process using geothermal hot water in a pretreatment to enhance conversion of wheat straw to liquid fuels and chemicals. Topical Report submitted to U.S. Department of Energy on Contract DE-A S07-79ID12051.

10. Miller, G.L. 1959. Use of DNSA reagent for determination of reducing sugars. Ana1. Chem., 31:426-428.

11. Pearl, I.A. 1967. The Chemistry of Lignin. Marce1-Dekker: New York, NY, pp 52-56.

12. van Soest, P.J. and R.H. Wine. 1968. Determination of lignin and cellulose in acid-detergent fiber with permanganate. J. Assoc. Off. Anal. Chem., 51:780-785.

13. Goering, H.K. and P.J. van Soest. 1970. Forage fiber analyses (apparatus, reagents, procedures, and some applications). Agriculture Handbook No. 379. U.S. Department of Agriculture: Washington, D.C.

14. Brook, C.A., R.H. Mariner, D.R. Mabey, J.R. Swanson, M. Guffanti and L.J.P. Muffler. 1979. Hydrothermal convection systems with reservoir temperatures $\geq 90^{\circ} \mathrm{C}$. pp $18-85$ in L.J.P. Muffler (ed.) Assessment of Geothermal Resources of the United States -- 1978. Geological Survey Circular 790. United States Department of the Interior: Washington, D.C. 
15. Akazawa, T. 1976. Polysaccharides. pp 381-403 in J. Bonner and J.E. Varner (eds.) Plant Biochemistry, Third Edition. Academic Press: New York, NY.

16. Harkin, J.M. 1973. Lignin. pp 323-373 in G. W. Butler and R. W. Bailey (eds.) Chemistry and Biochemistry of Herbage. Volume I. Academic Press: New York, NY.

17. Wilke, C.R., U.V. Stockar and R.D. Yang. 1976. Process design basis for enzymatic hydrolysis of newsprint. pp 104-114 in S.M. Barnett et al. (eds.) AIChE Symposium Series No. 158. Biochemical Engineering - Energy, Renewable Resources and New Foods. American Institute of Chemical Engineers: New York, NY.

18. Mande1s, M. and D. Sternberg. 1976. Recent advances in cellulase technology. J. Ferment. Techno1., 54:267-286. 